9 2INSTAAR, University of Colorado, Boulder CO 80309-0450 USA

10 (chris.jenkins@colorado.edu)

11

\author{
John A. Goff ${ }^{1}$, Chris J. Jenkins ${ }^{2}$, and S. Jeffress Williams ${ }^{3}$
} TX 78758 USA (goff@utig.ig.utexas.edu)

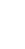

1

${ }^{3}$ U.S. Geological Survey, Woods Hole Science Center, Woods Hole MA 02543 USA (jwilliams@usgs.gov)

4

Submitted to Continental Shelf Research, March, 2007

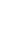

\title{
Seabed mapping and characterization of sediment variability using the usSEABED database
}

${ }^{1}$ Institute for Geophysics, Jackson School of Geosciences, University of Texas at Austin, Austin,

7 Abstract. We present a methodology for statistical analysis of randomly-located marine

sediment point data, and apply it to the U.S. continental shelf portions of usSEABED mean grain size records. The usSEABED database, like many modern, large environmental datasets, is heterogeneous and interdisciplinary. We statistically test the database as a source of mean grain 1 size data, and from it provide a first examination of regional seafloor sediment variability across

22 the entire US continental shelf. Data derived from laboratory analyses ("extracted") and from word-based descriptions ("parsed") are treated separately, and they are compared statistically and 
24 deterministically. Data records are selected for spatial analysis by their location within sample regions: polygonal areas defined in ArcGIS chosen by geography, water depth, and data sufficiency. We derive isotropic, binned semivariograms from the data, and invert these for estimates of noise variance, field variance, and decorrelation distance. The highly erratic nature of the semivariograms is a result both of the random locations of the data and of the high level of data uncertainty (noise). This decorrelates the data covariance matrix for the inversion, and largely prevents robust estimation of the fractal dimension. Our comparison of the extracted and parsed mean grain size data demonstrates important differences between the two. In particular, extracted measurements generally produce finer mean grain sizes, lower noise variance, and lower field variance than parsed values. Such relationships can be used to derive a regionallydependent conversion factor between the two. Our analysis of sample regions on the U.S. continental shelf revealed considerable geographic variability in the estimated statistical parameters of field variance and decorrelation distance. Some regional relationships are evident, and overall there is a tendency for field variance to be higher where the average mean grain size is finer grained. Surprisingly, parsed and extracted noise magnitudes correlate with each other, which may indicate that some portion of the data variability that we identify as "noise" is caused by real grain size variability at very short scales. Our analyses demonstrate that by applying a bias-correction proxy, usSEABED data can be used to generate reliable interpolated maps of regional mean grain size and sediment character. 


\section{Introduction}

The physical properties of seafloor sediments on the continental shelf are spatially variable on many scales due to a complex underlying geologic framework and seafloor processes: from regional-scale variations (10 to $100 \mathrm{~km}$ ), such as those associated with proximity to major depocenters or the shoreline, down to mesoscale variations (1 to $10 \mathrm{~cm}$ ), such as those associated with ripple bedforms. In between are variations associated with a multitude of bedform types and scales (e.g., sand ridges, rippled scour depressions, dunes, megaripples, ribbons), reworking and erosion, or patchiness caused by such factors as localized erosion, biologic processes (e.g., shell patches), bedrock outcrop, or glacial detritus (gravel patches). Spatial variability is related to process, and we seek, ultimately, to achieve a basic understanding of the geological response to the oceanographic and sedimentological processes acting on the seafloor. We seek as well to utilize that relationship as a predictive tool. In other words, if we understand the seabed environment sufficiently, can we make reliable predictions about the quantitative characteristics of sediment variability? Such a capability would have important applications in, for example, ocean acoustics, where regional seabed variability strongly affects acoustic response over long path lines (e.g., Lapinski and Chapman, 2005), or benthic habitats, where environmental heterogeneity is a particularly strong predictor of species richness (e.g., Kerr et al., 2001). Quantitative understanding of seafloor variability at all scales is also important for map making, in particular for applying techniques that reduce data uncertainty (Goff et al., 2006), and for geostatistical interpolation (e.g., kriging; Cressie, 1990).

Data quantity and coverage are the most significant challenges to investigating the variability of seafloor sediments. Spatial variability is a statistical measure of ensemble properties, quantified by such functionals as the power spectrum, covariance function or semi-variogram. 
Robust estimation of these types of functions requires large quantities of data sampled over a large range of spatial scales. However, that is very difficult to obtain. Despite years of advances in acoustic remote sensing (e.g., Pratson and Edwards, 1996), and increased sophistication of classification algorithms (e.g., Atallah and Probert Smith, 2004; Bartholomä, 2006), characterizing the physical properties of seafloor sediments remains a significant challenge. For example, although acoustic backscatter data are strongly related to sedimentary properties, the number of potential variables affecting backscatter are so large as to make the problem of seabed discrimination exceedingly difficult (e.g., Jackson et al., 1986; Ferrini and Flood, 2006). Furthermore, the seabed factors of greatest importance in determining backscatter appear to be very local in scope (e.g., Goff et al., 2000; 2004), so that global algorithms for determining sedimentary character from backscatter data will likely perform poorly. It remains necessary to directly sample sediments in order to measure properties consistently from one region to another. Unfortunately, direct sampling is very time consuming and expensive and, even with extensive effort, often results in a relatively small number of sample sites for any single field campaign. The issue of comprehensive data coverage of seabed samples for the U.S. continental margins is being addressed in a collaborative research effort between the U.S. Geological Survey and INSTAAR at the University Colorado (usSEABED; Williams, et al., 2003; Reid et al., 2005, 2006; Buczkowski et al., 2006). This work has resulted in a database methodology for assembling extant seabed observations (dbSEABED; Jenkins, 1997, 2002). Extensive effort has gone into collecting, evaluating, assembling, and publishing available records within published and unpublished data sets from federal and state agencies, universities, industry and individual researchers. The result is a combined U.S. database of such observations (Figure 1). Although coverage is far from uniform and is based on surveys spanning approximately the past 120 years, 
these collections provide, in many continental shelf and estuarine regions, a data set that is sufficient in quantity and coverage to robustly map seabed properties and to estimate spatial variability functions such as the semi-variogram. The usSEABED database is a unique resource that would not be possible to collect by individual investigators. The methods employed in the usSEABED project relate to a growing and necessary computational resource in environmental sciences: large aggregated, heterogeneous and interdisciplinary data bases (e.g., Osenberg et al. 1999; Jones et al. 2006).

Our primary goal for this paper is to statistically test the viability of the heterogeneous usSEABED database for mapping seabed properties and for investigating sediment variability on the seafloor. This is a test case for wider application to worldwide coverage. To maintain focus in our analysis, we will restrict consideration to mean grain size measurements of unconsolidated sediments (i.e., no outcrop observations) in an open-ocean (i.e., no estuary observations), continental shelf setting. Mean grain size is a commonly reported measurement in the dbSEABED databases, which provides a good opportunity to maximize data content in any given area. Mean grain size can also be related to other important physical parameters, such as bulk density, seismic velocity, and sediment transport potential (e.g., Stoll, 1977; Hamilton and Bachman, 1982; Ogushwitz, 1985).

Our secondary goal is to employ the results of our analysis in a preliminary investigation of variability as a function of geography and, to the extent warranted by the data, water depth. At this exploratory stage in our investigation we seek first to obtain an overall view of what sediment variability looks like on the US continental shelf. Future investigations, probably requiring a larger, global database, may seek to answer more refined questions regarding the relationship of sediment variability to environmental parameters such as shelf slope, shelf width, 
115 wave climate, proximity to sources/sinks, etc. The data employed here primarily permit only

116 regional interpretations. More detailed investigations, e.g., ground-truthing sonar backscatter

117 maps, would require extensive additional sampling. However, the methodology we describe can

118 be used on small or large spatial scales to integrate data from multiple sources.

119 While our primary goal may, on first consideration, appear straightforward, in reality it

120 presents significant and important challenges owing to the heterogeneous nature of the data base.

121 The usSEABED data base holds data that were collected by a large number of different

122 investigators at different times utilizing a range of methodologies. The issues that arise also

123 appear in aggregated bathymetric datasets of the seafloor (e.g., Jakobsson et al., 2002; Calder,

124 2006). In the case of the usSEABED data base these issues are of particular relevance:

125 (1) Mean grain sizes are reported in two fundamentally different ways: "extracted" and

126 "parsed". Extracted data are computed from grain size histograms determined by precise

127 analytical means (e.g., sieves, settling tubes, diffractometry). Parsed data are inferred through a

128 conversion by means of a fuzzy set theory (Zadeh 1965) of visual descriptions (i.e., including

129 coarse, medium or fine sand, gravel, silt, mud, clay, shells, etc.). Such inferences are less

130 precise, but in many regions constitute the majority of the data coverage and in some cases the

131 only data available.

132 (2) Parsed and extracted mean grain size measurements perform differently in various parts

133 of the grain size spectrum with respect to accuracy and precision. For example, while analytic

134 methods can accurately measure grain size contributions from $\sim 10 \mathrm{~mm}$ to $2 \mu \mathrm{m}$, visual

135 descriptions are limited to grain sizes above $\sim 20 \mu \mathrm{m}$, and so have lower accuracy in the fine grain

136 sizes (silt and finer). 
(3) Laboratory analyses of sediment grain size histograms sometimes exclude shell and gravel contents, and other difficult-to-treat components. This happens typically when a researcher is primarily interested in sediment transport or physical properties issues, and does not consider the shell content germane to the research (e.g., Poppe, et al., 2001; Moore et al., 2002). Visual descriptions typically do represent the presence of shell and gravel when it is present, hence a bias may arise between parsed and extracted determinations of mean grain size.

(4) Data within usSEABED are collected across several decades in most regions, so that temporal variability may be superimposed on spatial variability. In addition, navigational uncertainties have changed markedly through the years, from $>1 \mathrm{~km}$ for old star fixes and LORAN-navigated data, to $<100 \mathrm{~m}$ for satellite navigation, to $<10 \mathrm{~m}$ for GPS. Large uncertainties can lead to juxtaposition of different types of sediment where the natural heterogeneity is strong. At present, temporal information cannot be extracted from the usSEABED database.

Our challenge is to utilize this complex data set in a coherent and consistent manner, and to properly characterize uncertainty and bias in each of the types of data included in it. Many readers may question a priori the value of treating quantitatively a data set which is subjective by its very nature. But the value lies in the statistics of large numbers: a single estimate of mean grain size from a visual description may have little credibility, but many such estimates, when considered as an ensemble, can. In this paper we establish that credibility by demonstrating a quantitative, statistical relationship between the word-based and analytically-derived estimates of mean grain size. 


\section{Methods}

\subsection{Derivation of mean grain size from observations and samples}

The dbSEABED software deals with both analytical (numeric) and descriptive (word-based) data types, which pass outputs that are termed "extracted" and "parsed", respectively. Extracted mean grain size values are derived with minimal processing from the original records, whereas parsed values are formulated via recognition of the linguistic parts of sediment description leading to analysis of the meaning (e.g., Grune and Jacobs, 1990). Here we employ $\phi$ grain size units, where $\phi=-\log _{2}[\mathrm{~mm}$ size] (gravel is -8 to $-1 \phi$, sand is -1 to $4 \phi$, and mud is 4 to $12 \phi$ )

In the extraction stream of processing, we begin by nominating a standard (moment mean) to which other measures of grain size must conform, or be made to conform with, to be accepted as inputs. Those various measures include: median, Folk (1974) and Inman (1952) graphic 'means', geometric mean, and mode. The conformance of these measures is revealed by crosscomparisons using data collections of over 10,000 samples (including, for example, Poppe et al., 2005) where two or more have been determined together (Figure 2). The Folk and Inman graphic means do conform (and are acceptable as input), but modes do not (and are unacceptable).

Conformance to the moment mean standard can be improved during processing using an adjustment on the incoming data (e.g., Smith and McConnaughey, 1999).

In many datasets, analytic determinations of detailed grain size histograms are available instead of the mean value. In these circumstances, the moment mean grain size is calculated directly from the histogram. We have implemented a set of filters to reject analyses which purport to be of the entire sediment, but are actually limited to a certain instrumentation and fraction (e.g., to sand in the case of settling columns). Where a sediment mean grain size is 
reported in the data in addition to detailed grain size histogram, the reported mean takes precedence.

The possibility of a bias in analytical measures of mean grain size is raised because common practice for many investigators is to remove all carbonate content, including coarser shell hash, from a sample prior to analysis. This practice is highlighted in the USGS manual on grain size analysis (Poppe et al., 2001):

Whole or fragmented calcite secreting micro- and macro-organisms can bias the grain size distribution if they occur in significantly high concentrations. Because biogenic carbonates commonly form in situ, they usually are not considered to be hydraulically representative of the depositional environment from a textural standpoint (Reineck and Singh, 1980). Their presence alters the textural data and complicates interpretation. ... If limited to the gravel fraction, it is often easier to manually remove the fragments of bivalve shells and other biogenic carbonate debris ....

The reportage, or not, of shell material as part of the sample analysis is therefore a point-of-view issue. For purposes of hydraulic analysis, shells are considered unrepresentative of the processes under consideration, and so are simply ignored. For other purposes, such as understanding acoustic backscatter, the presence of shells can be a critical factor (e.g., Goff et al., 2004). Over the entire usSEABED database, however, it is important to consider the possibility of a bias in analytic measures of mean grain size due to the under-reportage of shell material.

Word-based data are treated with an algorithm which parses (recognizes) and analyzes (comprehends) text descriptions of the sediments and compiles an estimated grain size using fuzzy set theory memberships for lithologic and size terms (Jenkins, 1997). The input descriptions are held in original, although abbreviated terms. With the use of pointers and some special syntaxes, potential ambiguities in descriptions are resolved. Functional roles for terms as (geological material) objects, (property) modifiers, quantifiers and locators are recognized from the dictionary. A dictionary, organized as thesaurus, provides numeric and coded meanings to 
208 each term. Terms may be relevant/irrelevant and known/unknown in meaning for each parameter

209 (e.g., for grain size respectively: "fine sand" / "green", and "fine sand" / "sediment"). The

210 numeric meanings, including the grain size characteristics of described components, are

211 assembled in a linear weighting scheme (Jenkins, 1997, Fig. 2). During processing the unknown

212 parts are monitored and, if above 5\%, the parsing is aborted. Any term not in the dictionary also

213 causes an abort. More information on the parsing process is given in Jenkins (1997, 2002), Reid

214 et al. (2005, 2006), and Buckzowski et al. (2006).

215 Opportunities exist in the process to monitor how well the parser is performing. We use those

216 samples where word-based and measured analytical data are both available. A recent calibration

217 using 10,029 usSEABED samples yielded a correlation coefficient of +0.59 between extracted

218 and parsed mean grain size values. Across the same dataset (Figure 3) the median average

219 deviation was $0.9 \phi$. The ranges of confidence at $1 \sigma$ and $2 \sigma$ were 1.25 and 4.2 deviation in

220 absolute $\phi$.

\subsection{Data preparation and sampling}

Prior to statistical analysis, we process the mean grain size data in two ways: (1) "culling," which eliminates redundancies at any specific location and restricts consideration to only seafloor samples of unconsolidated sediments, and (2) definition of polygonal sample areas which restrict consideration to only samples that fall within areas that they define. Culling is required because usSEABED records frequently list multiple entries with identical coordinates.

228 This can occur with repeat measurements on a single surface sample, but also when different 229 subbottom samples are analyzed, such as from cores. We restrict consideration to "seafloor" 
$2310.5 \mathrm{~m}$ below the seafloor. Where we did encounter multiple seafloor grain size measurements at

232 a single location, they were simply averaged. Parsed and extracted measurements of mean grain

233 size are kept in separate data files, so that one type of measurement does not exclude the other

234 where both are made at the same location. We also restrict consideration to observations from

235 unconsolidated sediments. "Hard ground" observations (exposures of old, lithified material) do

236 not fit within the mathematical framework of mean grain size measurements. A complete

237 statistical treatment of seafloor terrains with outcrop exposures would require separate

238 characterization of both the unconsolidated sediments and the binary hard ground/soft ground

239 relationship. Such a treatment is beyond the present scope, but could readily be incorporated if

240 required for some applications. An example of statistical characterization of a binary field can

241 be found in Goff et al. (1994).

242 We define sample areas for statistical analysis to investigate geographic changes in sediment

243 variability. Choosing sample areas necessarily involves a balance among two competing factors:

244 geographic and statistical resolution. Geographic resolution is maximized by minimizing the

245 size of sample areas. Conversely, statistical resolution is maximized by increasing the number of

246 samples, which, given a preexisting data set, requires increasing the size of the sample area. As

247 a rule-of-thumb, we found that having at least 1000 well-distributed (i.e., not all clumped

248 together) samples in a sample area resulted in a semi-variogram estimate that was well-enough

249 resolved (i.e., not overly erratic) to obtain stable statistical parameter estimates; we used this as a

250 guiding factor for choosing the size of sample regions. This is not a hard-and-fast rule, however.

251 A region with fewer samples may be chosen if tolerance for statistical inaccuracy is higher, or if,

252 by enlarging the area further, one would unduly risk combining overly different geographic

253 environments into a single estimate. Some areas simply have too-few samples in them to include 
254 in this analysis; this includes large portions of the Pacific and Gulf of Mexico shelves. Other 255 than sample size, we also considered major geographic features (e.g., Cape Hatteras, NC or Cape 256 Cod, MA) and, where data coverage provided adequate support, water depth in defining sample

area boundaries. Jenkins and Goff (2007), in a statistical analysis of mean grain size data in the Adriatic Sea, separated the data by depth values and found that statistical parameters changed markedly across the 20-m isobath. For the usSEABED database, only the Atlantic shelf afforded sufficient coverage to utilize water depth to define sample areas. For those data, we also use the 20-m isobath as a boundary, as well as the 50-m and 100-m isobaths to distinguish between inner, middle and outer continental shelf sample areas. Overall we defined 31 sample areas for the usSEABED database in U.S. continental shelf waters (19 in the Atlantic, 6 in the Gulf of Mexico, and 6 in the Pacific).

ArcGIS (Ormsby et al., 2001) was used to define polygonal sample areas, and then to select usSEABED data points within those areas for statistical analysis. An example from the midAtlantic Bight is presented in Figure 4. We first import a freely-available US political boundary shape file to define the coastline. Bathymetry is extracted from the NOAA (2007) Coastal Relief Model directly into an ArcGIS-compatible grid format. Upon loading the bathymetry into ArcGIS, we use the contour tool (in the spatial analyst tool box extension) to determine the 20, 50, and $100 \mathrm{~m}$ contours for display. These are subsequently used to guide our choice of polygonal sample areas. The culled usSEABED mean grain size values, both parsed and extracted, are loaded into ArcGIS for display. Polygonal areas are then defined within a new shape file using the interactive graphics capabilities of ArcGIS. In the example shown in Figure 4, the Hudson Shelf Valley was excluded from the sample areas because it is, in essence, a geologic province unto itself: an anomalous region of fine grained sediments that is a result of 
277 the unique presence of the shelf valley across the continental shelf morphology (Vincent et al., 278 1981; Harris et al., 2003). Figure 5 displays all the sample areas defined on the continental shelf

279 for the usSEABED database, color coded by the average mean grain size of the parsed records in 280 those areas. The areas are identified numerically for reference to Table 1, which lists grain size 281 statistics for each region derived in the following sections.

\subsection{Semivariogram analysis of data field}

\subsubsection{Computation of the semi-variogram}

The semivariogram is a common tool for geostatistical characterization of a data field (e.g., $S(\mathbf{L})$ is defined by:

$$
S(\mathbf{L})=\frac{1}{2} E\left[(d(\mathbf{L})-d(\mathbf{X}+\mathbf{L}))^{2}\right]
$$

where $\mathrm{E}[]$ is the expected value, and $d(\mathbf{x})$ is a zero-mean data value at location $\mathbf{X}$. In practice, we typically remove a trend field from the data over a sample area by fitting a bilinear surface (Wessel and Smith, 1998) to the data and subtracting it. Equation (1) assumes that the field is 292 statistically homogenous; i.e., that statistical properties are not a function of X. Removal of a trend surface, as described previously, helps to enforce this assumption. The semivariogram is

294 related to the covariance function $C(\mathbf{L})$ by the simple relationship $S(\mathbf{L})=H^{2}-C(\mathbf{L})$, where $H^{2}$ is 295 the field variance.

Although this paper is focused on situations where the field data are randomly (meaning: not

297 located on a regular grid) and sparsely located in space, it is instructive to first consider the 298 formulation for estimating the discrete semivariogram from field data $d_{i, j}$ that are sampled fully 


$$
\hat{S}_{k, l}=\frac{1}{2\left(N_{x}-k\right)\left(N_{y}-l\right)} \sum_{i=1}^{N_{x}} \sum_{j=1}^{N_{y}}\left(d_{i, j}-d_{i+k, j+l}\right)^{2},
$$
where the lag vector is defined by $\mathbf{L}=(k \Delta x, l \Delta y)$. The semivariogram (or covariance) estimated in this way is generally a smoothly-varying function by virtue of the fact that proximal values are highly correlated with each other (Goff and Jordan, 1989). This can be understood intuitively by recognizing that, for example, the formulas for $\hat{S}_{k, l}$ and $\hat{S}_{k, l+1}$ utilize nearly all the same $d_{i, j}$ values, and the $d_{i+k, j+l}$ values are likely to be only slightly different from the $d_{i+k, j+l+1}$ values.

Estimating the semivariogram from randomly-located data is not as straightforward; it must be accomplished with a binning method. In addition, sufficient support of two-dimensional characterization of the semivariogram from generally sparse, randomly-sampled data is generally not available. We therefore restrict our attention here to the isotropic, one-dimensional semivariogram, which is a function of the lag distance $L=|\mathbf{L}|^{2}$. We define bins using a bin size $\Delta L$, where the $k^{\text {th }}$ bin is defined by the range $(k-1) \Delta L \leq L<k \Delta L$. Assume we have randomlylocated field data points, $d\left(\mathbf{X}_{i}\right), i \in 1, N$, in a sample area. We express the semivariogram estimation via:

$$
\hat{S}_{k}=\frac{1}{N_{k}} \sum_{i=1}^{N} \sum_{j=1}^{N} I_{i, j}(k) d\left(\mathbf{X}_{i}\right) d\left(\mathbf{X}_{j}\right)
$$

where

318 and 


$$
N_{k}=\sum_{i=1}^{N} \sum_{j=1}^{N} I_{i, j}(k) .
$$

An example semivariogram estimated from a sample area of the Atlantic usSEABED database, computed using equations (3)-(5), is displayed in Figure 6. Here and elsewhere we employ a lag bin size $\Delta L$ of $200 \mathrm{~m}$. For most regions we examined, this bin size typically results in bin populations (determined by the number of point pairs whose lag distance falls within the bin) of $\sim 1 / 2$ to 2 times the total data population of the region (although fewer at the shortest lag distances). A defining characteristic of this and all other such examples is the very high level of erraticity (i.e., strong variability from one discrete lag value to the next). This observation stands in sharp contrast to smoothly-varying semivariograms typically derived from regularly-sampled data using equation (2). The fundamental reason for this behavior is that the values of $\hat{S}_{k}$ are very different sets of data values, rather than very similar sets as in equation (2) for regularly

332 sampled data. The value $N_{k}$ is itself a random number, which can change substantially from one 333 lag index to the next. High levels of data uncertainty (noise) can also contribute significantly to 334 the erraticity of the semivariogram.

\subsubsection{Parameter estimation}

337 We estimate second-order statistical properties of the data field through an iterative, 338 weighted, least-squares inversion of the semivariogram (e.g., Menke, 1989). Following the 339 notation of Menke (1989), we define $\mathbf{d}$ as the "data" vector of semivariogram estimates $\hat{S}_{k}$, $340 \quad \mathbf{m}_{n}^{\text {est }}$ as the vector of model parameters at the $n^{\text {th }}$ iteration, and $\mathbf{g}\left(\mathbf{m}_{n}^{\text {est }}\right)$ as the vector of model 
341 predictions from those parameters. The iterative, linearized inversion formulation is then

342 expressed as: at $r=0$ is zero for $v=1$ and infinite for $v=0 . G_{1 / 2}(r)$ is simply an exponential function. The

where $K$ is a lag scale parameter and the $G_{v}$ is defined by

where cov $\mathbf{d}$ is the covariance matrix of the data vector, and the sensitivity matrix $\left[\mathbf{G}_{n}\right]_{i j}=$ $\partial g_{i} / \partial m_{j}$ is evaluated at $\mathbf{m}_{n}^{e s t}$.

We fit the one-dimensional, semivariogram form of the von Kármán statistical model (e.g., Goff and Jordan, 1988), with white noise variance, $N^{2}$, added. In discrete form, where $L=k \Delta L$, this can be written as

$$
S(k \Delta L)=N^{2}+H^{2}\left[1-G_{v}(K k \Delta L) / G_{v}(0)\right]
$$


361 dimension associated with Equation (7) is $\mathrm{D}=2-v$ for profiles and $3-v$ for surfaces (Goff and 362 Jordan, 1988).

363 The lag scale parameter, $K$, largely determines how quickly the field decorrelates with 364 increasing lag (i.e., how quickly the semivariogram approaches the sill), although the order 365 parameter also has an influence. A decorrelation length, $\lambda$, can be defined by the width (second 366 moment) of the covariance (Goff and Jordan, 1988):

$$
\lambda=\frac{2 \sqrt{2(v+1 / 2)}}{K} .
$$

368 The decorrelation length is a physically intuitive parameterization of the approximate width of 369 the principal structures of the field.

370 Partial derivatives for the covariance form of the von Kármán were calculated by Goff and 371 Jordan $(1988 ; 1989)$, and are easily converted to the semivariogram form of the model.

372 The weighted inversion formulation also requires identification of a data covariance matrix 373 (cov d in Equation 6), which involves defining the fourth moment of the field data (Goff and 374 Jordan, 1989). This is a tractable computation for regularly sampled data, but becomes very 375 difficult for randomly located data. However, we infer from our observation that these 376 semivariograms are highly erratic, and we can reasonably assume that the data points are largely 377 uncorrelated with each other. We thus approximate the data covariance with a diagonal matrix, 378 where the elements are defined by the semivariogram error variance. We estimate these 379 elements empirically, employing two metrics: (1) the variance of the misfit between the 380 semivariogram estimated from the data and the semivariogram model, which is iteratively 381 reduced during the least-squares inversion procedure, and (2) the number of data pairs, $N_{k}$, that 382 are used to estimate the $k^{\text {th }}$ semivariogram bin. The error variance for the bin average is 
383 expected to be proportional to the inverse of the number of sample points for that bin. We define

$384 E_{A}^{2}$ as the average error variance,

$$
E_{A}^{2}=\frac{1}{N_{b}} \sum_{k=1}^{N_{b}}\left(\hat{S}_{k}-S(k \Delta L)\right)^{2},
$$

where $N_{b}$ is the number of semivariogram estimation bins, and $\mathrm{S}(k \Delta L)$ is the model function defined in Equation (7), updated iteratively by the inversion Equation (6). We further define $N_{A}$ as the average number of bin samples:

$$
N_{A}=\frac{1}{N_{b}} \sum_{k=1}^{N_{b}} N_{k}
$$

The bin error variance is then estimated via

$$
E_{k}^{2}=E_{A}^{2} \frac{N_{A}}{N_{k}}
$$

and these values are used to define the diagonal elements of the semivariogram covariance matrix. We often find that the lowest lag values of the semivariogram are highly erratic owing to a scarcity of samples in those bins. The bin error formulation of Equation (12) sufficiently reduces the weight of such values so that they do not adversely affect the inversion result.

The erratic nature of the semivariograms estimated from randomly located data unfortunately make accurate estimation of the $v$ parameter (i.e., the fractal dimension) a nearly impossible task, in that the inversion quickly becomes unstable. The value of $v$ typically needs to be fixed to enable stable estimation of the other parameters, and for these data examples we choose $v=0.5$ (fractal dimension of 1.5 for a profile, 2.5 for a surface), which is identical to an exponential model. 
Figure 6 demonstrates a best-fit semivariogram model employing the method described above. The inversion formulation also provides estimates of the errors on model parameters (Menke, 1989):

$$
\left[\operatorname{cov} \mathbf{m}^{e s t}\right] \cong \mathbf{G}_{n}^{-g}[\operatorname{cov} \mathbf{d}] \mathbf{G}_{n}^{-g \mathrm{~T}}
$$

However, errors computed by this formulation must be considered underestimates because our assumption of uncorrelated semivariogram estimates is not strictly correct. Realistic $1-\sigma$ errors for $N^{2}$ and $H^{2}$ are $\sim 10 \%$ of the sill value (the sum of $N^{2}$ and $H^{2}$ ), and for decorrelation length are $\sim 25-50 \%$ (generally increasing with the decorrelation length).

\section{Extracted vs. Parsed mean grain size value comparison}

Our most fundamental issue in utilizing the usSEABED database mean grain size values is the comparability of extracted and parsed forms of measurements. In this section, we make two forms of comparison: (1) a direct comparison of proximal values, and (2) comparison of statistical parameters in sample areas that are well-covered by both record types.

\subsection{Direct comparison of proximal values}

We form extracted/parsed mean grain size pairs for comparison by finding, for each extracted measurement, the nearest parsed measurement no greater than $200 \mathrm{~m}$ away. No comparison is made for pairs greater than $200 \mathrm{~m}$ distant. More than 6,900 such proximal comparisons can be made over the entire usSEABED database (Figure 7), many of which are collocated. Figure 7 displays a significant amount of scatter, but nevertheless indicates a positive relationship between the two types of measurements of mean grain size. To better characterize this relationship, we have averaged the plotted points in two ways: (1) for each 1- $\phi$ extracted bin, we 
425 have determined the average parsed mean grain size, and (2) for each 1- $\phi$ parsed bin, we have 426 determined the average extracted mean grain size. The vast majority of samples fall within the 427 range $\sim 1-7 \phi$, and within this range both forms of averaging consistently indicate that parsed 428 measurements tend to have lower $\phi$ values (coarser mean grain sizes) than extracted measurements, typically by $\sim 0-1 \phi$. This indicates a bias in one of the two measurement types. The average extracted/parsed bin averages diverge, however, at both ends of the $\phi$ scale. At the upper end (finer grain size), extracted mean grain sizes reach values as high as $10 \phi$, whereas the parsed mean grain sizes are limited to $\leq 7 \phi$. This can be explained by the fact that the presence of "clay" $(\leq 8 \phi)$ cannot be verified in visual observations. Analytic methods, however, are able to discern finer grain sizes. At the lower end (coarser grain sizes), we observe that low$\phi$ parsed measurements are generally not matched by low- $\phi$ extracted measurements, and likewise that low- $\phi$ extracted measurements are not generally matched by low- $\phi$ parsed measurements (although there are far more examples of the former than the latter). The disparities worsen with decreasing $\phi$ (increasing grain size). We can envision two possible explanations for this observation: (1) that gravel/shelly patches tend to be spatially very confined, so that even proximal measurements can have large disparities, or (2) that the reporting of the gravel portion of samples in the usSEABED records is not very consistent, and worse for extracted measurements than for parsed measurements although examples of each are probable.

\subsection{Comparison of statistical parameters}

Of the 31 sample areas defined for the usSEABED database, 12 had sufficient coverage (see discussion in Section 2.2) of both parsed and extracted mean grain sizes to robustly estimate the variogram for inversion of statistical parameters. Figure 8 shows three such comparisons with 
448 contrasting results. Figure 8a presents what may be considered the ideal situation: the

449 semivariograms estimated from both parsed and extracted mean grain sizes are nearly identical

450 in shape, as evidenced by the similarity of the field variance and decorrelation length parameters.

451 The only substantive difference between the two is that the level of noise variance is higher in

452 the semivariogram estimated from the parsed data, in accordance with expectations.

$453 \quad$ Figure $8 \mathrm{~b}$ presents a situation where the field variance is much larger for the parsed data

454 than it is for the extracted data. Otherwise, as with Figure 8a, the decorrelation lengths are very

455 similar, and parsed data exhibit greater noise variance. The difference in field variance could

456 have a number of causes, including the possibility that coarse fractions are under-reported for the

457 extracted data.

$458 \quad$ Figure 8c presents a third different case: here the field variance of the extracted mean grain

459 sizes are much larger than for the parsed data. On the other hand, the "sill" value (the maximum

460 value approached by the semivariogram) of the parsed semivariogram is $\sim 1 \phi^{2}$ larger than for the

461 extracted semivariogram, and the noise variance of the parsed data is much larger than can be

462 reasonably explained by data uncertainty. The evidence here suggests that a significant portion

463 of the true field variance in the parsed data is being expressed as uncorrelated (noise) variance.

464 The reasons for this are not clear, but could be related to spatial undersampling of real features or 465 to location uncertainty in older data sets.

466 The primary lesson to be learned from the examples shown in Figure 8 is that the relationship

467 between parsed and extracted measurements of mean grain size cannot be determined on a

468 national or global scale, but rather must be determined on a case-by-case, region-by-region basis.

469 Nevertheless, it may be possible to utilize these sorts of comparisons to formulate a local

470 conversion factor between the two types of data measurements. 

confidence $=99 \%$ ) with no obvious biases.

Figure 9 displays graphs of parsed versus extracted statistical parameters (including the average mean grain size) for the 12 sample areas well covered by each type of data. In the comparison between average mean grain sizes (Figure 9a), we again observe the tendency, noted in Figure 7, for the parsed values to be less than the extracted values. Otherwise the averaged mean grain size for the regions are strongly correlated (correlation coefficient of +0.89 , with confidence $>99 \%$ ). In the comparison of field variance (Figure $9 b$ ), we find at the lower values a tendency for the parsed values to increase faster than the extracted values. That trend appears to reverse, however, at the larger field variance values. On the other hand, the two largest field variances for the extracted samples, one of which is the example shown in Figure 8c, correspond to the two anomalously large noise variances in the parsed data (Figure 9c). If, as we argued earlier, these sample areas are cases where a significant amount of the parsed field variance is being expressed as noise variance, then these two anomalous values in Figure $9 \mathrm{~b}$ would plot much closer to the 1:1 line (correlation coefficient of +0.83 , with confidence $=97 \%$ ). Aside from these two anomalous values, the noise variances in Figure 9c display a clear pattern of larger parsed values than extracted values (average difference $0.43 \phi^{2}$ ), and furthermore exhibit a strong positive correlation between parsed and extracted noise variances (correlation coefficient of +0.80 , confidence $=99 \%$ ). We will consider the causes for this correlation, which is unexpected, in the following section. The decorrelation lengths (Figure 9d) display considerable scatter, as befits the least well-resolved statistical parameter, but generally display a positive correspondence between the two types of measurements (correlation coefficient +0.54 , with 


\section{Results of statistical analysis}

Our estimates of field variance and decorrelation length scale within the usSEABED continental shelf sample areas (Figure 5) are listed in Table 1 and summarized graphically in Figures 10 and 11, respectively. In sample areas for which we were able to obtain estimates from both parsed and extracted data records, the higher of the two field variance values were used for display in Figure 10. As noted earlier and in Figure 9b, most of the higher field variances were recorded with the parsed data, and we speculate is largely due to under-reportage of coarse fraction in analytic methods used for the extracted data. The two primary exceptions (Figure 9b) are those where an unrealistically large portion of the total parsed field variance is accounted for by the noise variance, and in these cases we assume that the larger field variances from the extracted data are more representative. For the display of decorrelation length scales in Figure 11 we average the values from parsed and extracted data sets in regions where both are estimated, weighted by the number of samples of each. Geographically, we can use these plots to make several important observations:

(1) While the carbonate sands of the southeast and southwest Florida shelf and the siliciclastic sands of the U.S. Atlantic shelf south of Cape Cod are both among the largest overall mean grain sizes (Figure 5), they present strongly contrasting statistical behaviors. The grain size variance (Figure 10$)$ of the Florida shelf is relatively large $\left(\sim 1.5-3 \phi^{2}\right)$, and the decorrelation lengths $(<8 \mathrm{~km}$; Figure 11) are among the shortest observed. With the exception of regions just north of Cape Hatteras, the U.S. Atlantic shelf sediments exhibit low variance $\left(<1 \phi^{2}\right.$; Figure 10), and a large range of decorrelation lengths (Figure 11). There is no evident relationship between decorrelation distance and water depth, in contrast to the observations of Jenkins and Goff (2007) for the sediments of the Adriatic sea. The high variance and short decorrelation 
516 scales on the Florida shelf imply that there is less spatial predictability in these sediments than

517 most anywhere else. Short-scale patchiness of shell beds may be a contributing factor. By

518 contrast, the U.S. Atlantic shelf exhibits some of the highest grain size predictability (not

519 counting "hard-ground" outcrops, such as are know to be present on the Carolina shelf, for

520 example; Thieler et al., 1995), owing to the low variances and larger decorrelation length scales.

521 (2) Finer-grain size regions appear to exhibit moderate to large variances. The sediments off

522 Cape Cod and within the Gulf of Maine, which are strongly influenced by glacial detritus

523 deposited by Late Pleistocene ice sheets (Emery and Uchupi, 1984; Poppe at al., 2003), exhibit

524 the largest variances found in our analysis $\left(\sim 3-10 \phi^{2}\right)$. Most of these sample regions have

525 average mean grain sizes $>2 \phi$, with the exception of $<50 \mathrm{~m}$ water depth regions both north and

526 south of Cape Ann, MA and directly off Cape Cod. In these areas it is not uncommon for

527 samples to alternate between fine grained muds or sands and coarser material, up to and

528 including gravel. Along the U.S. Pacific shelf and Gulf of Mexico shelf, west of Florida,

529 average mean grain sizes are generally $\sim 2-5 \phi$, and variances are mostly between $\sim 0.8$ and $2.7 \phi^{2}$.

530 (3) Aside from the evident association of shorter decorrelation lengths along the Florida

531 shelf, decorrelation lengths in general do not exhibit much in the way of regional continuity.

532 We utilize inter-parameter graphs (Figure 12) to explore the relationships between the

533 different statistical parameters estimated from the usSEABED continental shelf sample regions.

534 Figure 12a displays average mean grain size in each sample region plotted against field variance.

535 At first examination, there appears to be no trend between the two parameters. However, the

536 scatter in the plot is largely driven by the regions with the largest field variance values. These

537 regions are localized in the Gulf of Maine and Florida shelf areas, where we have cause to

538 presume that the enhanced variance is being driven by the presence of gravel or shell patches. If 
we remove all results from these two regions (Figure 12b), a clear positive correlation is observed between the average and field variance of the mean grain size in $\phi$ (which translates into an inverse correlation in $\mathrm{mm}$ ), with separate correlations are noted for parsed and extracted data results (correlation coefficients are +0.74 , with $99 \%$ confidence, and +0.66 , with $99 \%$ confidence for extracted and parsed, respectively), with the parsed samples exhibiting larger variances and/or coarser grain sizes (lower $\phi$ values). Regression lines for both parsed extracted measurements are also plotted on Figure 12b (for parsed: $y=0.157+0.586 x$; for extracted: $y=$ $0.154+0.287 x)$

Other inter-parameter graphs (decorrelation length vs. average mean grain size in Figure 12c; decorrelation length vs. mean grain size variance in Figure 12d; noise variance vs. average mean grain size in Figure 12e; and noise variance vs. mean grain size in Figure 12f) evince no clear correlations. We include here measurements of the noise variance plotted against the average and field variance. Earlier we noted an evident correlation between the noise variances derived by parsed and extracted records of mean grain size. There is no self-evident reason why such a correlation should exist. One possibility is that noise variance for each is somehow related to the physical parameters of the mean grain size field, so that both parsed and extracted noise variances are responding to a common input. The lack of correlations noted in Figures $12 \mathrm{~d}$ and $12 \mathrm{f}$ does not support this supposition, at least as related to the correlated component of the field. We cannot, however, discount the possible existence of an uncorrelated component to the field, or at least a component which has a shorter decorrelation scale than can be measured by the by the available spatial density of samples. If such a component does exist, it would contribute to what we identify as the noise variance, both for extracted and parsed measurements, thereby inducing a correlation between the two. 


\section{Example application: mapping grain size character of the Long Island shelf}

The Long Island shelf region exhibits complex sediment character and distribution due to several factors such as: proximity to terminal moraine glacial deposits that compose Long Island, underlying framework geology, and transgressive marine processes associated with approximately $100 \mathrm{~m}$ of Holocene sea level rise (Williams, et al., 2006a). In addition to providing basic information about the spatial variability of a field, the semivariogram characterization provides important constraints on the production of maps through interpolation of point data. Ordinary kriging is a well-known interpolation methodology that explicitly utilizes the semivariogram in a weighted averaging algorithm (e.g., Cressie, 1990; Deutsch and Journel, 1992). The primary advantage Kriging has over deterministic interpolation methods, such as splines (e.g., Smith and Wessel, 1990), is that it provides a geostatistical framework for estimating the error of the prediction. Other interpolation methods could be used, however, with similar results for map generation. The kriging solution can be identified as the expected value at an unsampled location given the data constraints at proximal and distal locations. We demonstrate kriging of the usSEABED mean grain size data on the Long Island shelf to $50 \mathrm{~m}$ water depth (Figure 13). This area includes two of our defined sample regions, from 0-20 m (area 5) and 20-50 $\mathrm{m}$ (area 11). The parsed and extracted semivariogram characterizations of the 0-20 m sample region are shown in Figure 8a. The 20-50 m semivariogram characterizations are nearly identical, allowing us to apply a single statistical characterization to the kriging interpolation of the combined area. Because the field variances and decorrelation lengths derived from both parsed and extracted records are very similar, we conclude that it is appropriate in this case to combine the two types of records for the interpolation with a simple 
static shift, a "bias-correction proxy", to accommodate differences in the mean. Here that proxy is $\sim 0.5 \phi$, which is the approximate difference between the average extracted and parsed mean grain sizes in these regions (Table 1). We subtracted this value from all of the extracted records under the assumption that the extracted values underreport coarse fraction. This is speculative, however, and other workers may consider other rationales for choosing how to apply the proxy. The resulting kriged field is shown in Figure 13a.

A direct interpolation of the usSEABED mean grain size records is not necessarily desirable, however. With a parsed record noise variance that is nearly double the field variance (Figure 8; Table 1), many positive and negative spikes appear in the mappings. Goff et al. (2006) recently formulated a methodology for resampling noisy, correlated data to mitigate the spikes prior to resampling. The method employs both a characterization of the field semivariogram (as characterized by the field variance, decorrelation distance and fractal dimension), and an a priori characterization of the data uncertainty. Here we assume that the data uncertainty is wellcharacterized by the square root of our estimation of the noise variance. Figure 13b displays the results of kriging the resampled mean grain size data, clearly demonstrating a significant reduction in the number and intensity of spikes.

For the Long Island shelf data set, the accuracy of the mean grain size map can be checked qualitatively by comparing it to existing USGS backscatter data collected off western Long Island, NY (Schwab et al. 2000). In Figure 14, we compare overlapping components of the two maps. Bearing in mind the much lower spatial resolution of the seafloor sample map (of order kilometers) as compared to the acoustic backscatter (of order meters), there are evident associations of coarser grain sizes on the mean grain size map to regions of higher backscatter intensity (i.e., sand shoals). This is particularly notable in the central part of the figure. A 
608 quantitative comparison between the two mapped values is presented in Figure 15. Considerable 609 scatter is evident in this direct comparison, likely due both to the very different spatial 610 resolutions of the two maps and to the generally erratic behavior of backscatter data (e.g., Goff et 611 al., 2004). As noted previously, temporal variability of the usSEABED records may also 612 contribute to spatial erraticity of the mean grain size values. The resampling algorithm mitigates 613 these effects. The binned mean values (Figure 15), however, present a much clearer relationship. 614 We first observe a general decrease in backscatter intensity with decreasing grain size going 615 from very coarse sand $(\sim-0.5 \phi)$ to the medium/fine sand transition $(\sim 2 \phi)$. This observation is 616 consistent with what can be most readily observed qualitatively on Figure 14. At grain sizes 617 finer than $2 \phi$, however, an inverted trend (increasing backscatter with decreasing grain size) is 618 noted. A similar reversal in backscatter-versus-grain size trend, also occurring at fine-sand grain 619 sizes, was noted by Goff et al. (2005; Figure 4)) within the Martha's Vineyard Coastal 620 Observatory. We speculate that fine sands mark a transition between backscatter dominated by 621 surface/grain size roughness and volumetric heterogeneity (e.g., Jackson et al., 1986). That is, at 622 finer grain sizes, the acoustic energy is able to penetrate deeper into the sediments, and in so 623 doing intersects with a greater cross-section of potential scatterers. Whether or not this is the 624 case, however, the consistency of trends with another grain size-versus-backscatter study in a 625 similar inner-shelf environment provides a measure of validation for our usSEABED-based 626 mean grain size map of the Long Island shelf.

\section{Conclusions and Discussion}

In this paper, we have presented a methodology for statistical analysis of randomly-located, noisy point data, and applied it to the usSEABED records of mean grain size on the continental 
631 shelf seabed. The method has proven robust at obtaining estimates of the field variance and 632 decorrelation distance, as well as estimates of the data noise variance. However, the erratic 633 nature of semivariograms generated from such randomly-located data generally precludes robust 634 estimation of the fractal dimension.

635 As primary component of the study we examined the suitability of the aggregated 636 usSEABED data collection for mapping and variability analysis. Our deterministic and 637 statistical comparison between the parsed and extracted forms of mean grain size data reveal 638 some differences. As expected, the noise variance tends to be larger for the parsed records (by $639 \sim 0.2-1.0 \phi^{2}$ ), which reflects a higher level of uncertainty in the measurements. Greater temporal 640 variability (i.e., timing of sample collection) may also be important. At present, temporal 641 information cannot be extracted from the usSEABED database, but it is likely that the word642 based data records span a much greater range in dates. Any temporal effects on grain size 643 measurements (e.g., changes in sedimentary conditions, changes in navigational resolution) will 644 presumably factor into the data uncertainty. Higher levels of uncertainty in the parsed 645 measurements might also be related to the likelihood that they are more likely to incorporate a 646 wider set of materials, such as coarse biogenics.

647 In general, the extracted mean grain sizes tend to exhibit higher $\phi$ values (finer grain sizes), $648 \sim 0.5 \phi$ on average, and lower field variance relative to the parsed mean grain sizes. Both 649 observations might be explained by a tendency for grain size analysts to discard the very coarsest 650 fraction of a sediment, particularly if it contains shell material. These differences between 651 parsed and extracted measurements are, however, somewhat regionally dependent, and it is not 652 possible to formulate a precise universal conversion factor between the two. Nevertheless, if 653 sufficient numbers of each type of data exist within a particular sample region, it should be 
654 possible to empirically define a local conversion so that the two types of data can be used together, along with their respective uncertainties, for quantitative applications such as mapping.

Our analysis of sample regions for the usSEABED records on the continental shelf reveal considerable geographic variability in the estimated parameters of field variance (Figure 10) and decorrelation distance (Figure 11). High field variances and short decorrelation lengths on the Florida shelves may indicate a high level of patchiness due to shelly material. Very high variances in the Gulf of Maine may be a result of residual glacio-fluvial gravel patches interspersed with fine-grained sediments. Elsewhere, we observe a fairly strong inverse relationship between the average mean grain size and the field variance (expressed as a positive correlation in $\phi$ units). We are uncertain as to the cause of this correlation.

Other than the small values on the Florida shelf, the estimated decorrelation length scales do not present coherent geographical relationships. Unlike the results of Jenkins and Goff (2007) for the analysis of mean grain size measurements in the Adriatic Sea, we do not find evidence on the U.S. Atlantic margin for any consistent depth relationship for this parameter (other regions were insufficiently sampled to discriminate sample regions based on water depth). We believe that analysis of more sample areas from a greater variety of settings will be needed to decipher the primary influences on decorrelation length scale. We suggest here that it may be controlled by competing relationships of geologic inputs (e.g., sediment facies), which probably tend toward larger decorrelation length scales, and oceanographic reworking, which probably tends toward shorter length scales (e.g., bedforms).

In Figure 9c we presented evidence that the noise variance estimated from parsed and extracted mean grain size measurements are correlated. Assuming the noise variance is related only to the data uncertainty, there is no reason to expect such a correlation, suggesting that noise 
677 is somehow influenced by the properties of the field. However, no such evidence could be found 678 in our interparameter plots presented in Figures 12e and 12f. To explain these observations, we 679 hypothesize that a very short-scale of field variability exists that is superimposed on the larger 680 scale of variability that we discern through estimate of the decorrelation length of the 681 semivariogram, and that the decorrelation length of this shorter scale variability is shorter than 682 the resolution scale of the sample data. In other words, the portion of data variability that we 683 identify as "noise" includes both a real field component and a data uncertainty component. If 684 true, then we cannot directly distinguish between the two, although we may be able to infer the 685 field component if we are able to postulate globally constant values of uncertainty for parsed and 686 extracted measurements. More data analysis will be required to determine if that is the case.

687 Our example using the Long Island shelf data (Figures 13, 14) shows that usSEABED can 688 reliably be utilized for creating maps of seafloor mean grain size and possibly other sediment 689 characteristics. Due to the noisy character of the data, some sort of filtering or other noise 690 reduction algorithm (e.g., Goff et al., 2006) is recommended prior to map generation. To 691 combine the parsed and extracted measurements, a bias correction proxy must be applied, and 692 such a correction should be evaluated individually for each region of interest. For the Long 693 Island shelf data, a simple mean correction of $0.5 \phi$ was found to be suitable because the 694 semivariogram statistics were otherwise found to be very similar between the two types of data. 695 Recognizing that coarse content is excluded from many analytic results, we applied the 696 correction by subtracting it from the extracted data. Other regions, however, exhibit significant 697 difference in both the mean and variance of parsed versus extracted mean grain size values, and 698 in those cases a more complex bias correction proxy must be devised. 
700 Acknowledgments. The authors thank the Office of Naval Research for support under grants 701 N00014-05-1-0079 (JAG) and N00014-05-1-0080 (CJJ), and the USGS/Coastal and Marine

702 Geology Program (SJW). We particularly wish to thank the many people and institutions who 703 have contributed their data to usSEABED. We acknowledge important assistance with the 704 usSEABED database by Matthew Arsenault, Jane A. Reid, Halimeda Kilbourne, Jamey Reid and 705 Brian Buczkowski of the USGS. Helpful comments on an earlier draft were provided by Wayne 706 Baldwin and Walter Barnhardt for an internal USGS review, and two anonymous journal 707 reviewers. UTIG contribution \# 


\section{References}

Adler, R.J., 1981. The Geometry of Random Fields. John Wiley, New York, 280pp.

Atallah, L., Probert Smith, P.J., 2004. Automatic seabed classification by the analysis of sidescan sonar and bathymetric imagery. IEEE Proceedings on Radar and Sonar Navigation 151, 327336.

Bartholomä, A., 2006. Acoustic bottom detection and seabed classification in the German Bight, southern North Sea. Geo-Marine Letters 26, 177-184.

Buczkowski, B.J., Reid, J.A., Jenkins, C.J., Reid, J.M., Williams, S.J., Flocks, J.G., 2006. usSEABED: Gulf of Mexico and Carribbean (Puerto Rico and U.S. Virgin Islands) Offshore Surficial Sediment Data Release. U.S. Geological Survey Data Series 146, version 1.0, Online at http://pubs.usgs.gov/ds/2006/146/.

Calder, B., 2006. On the uncertainty of archive hydrographic data sets. IEEE Journal of Ocean Engineering 31, 249-265.

Christakos, G., 1992. Random field models in Earth sciences. Academic Press Inc., San Diego, $474 \mathrm{pp}$.

Cressie, N., 1990. The origins of kriging. Mathematical Geololgy 22, 239-252.

Deutsch, C.V., Journel, A.G., 1992. GSLIB geostatistical software library and user's Guide. Oxford University Press, New York, 340pp.

Emery, K.O., Uchupi, E., 1984. The Geology of the Atlantic Ocean. Springer-Verlag, New York, $1050 \mathrm{pp}$. 
729 Ferrini, V L., Flood, R.D., 2006. The effects of fine-scale surface roughness and grain size on $730 \quad 300 \mathrm{kHz}$ multibeam backscatter intensity in sandy marine sedimentary environments. Marine Geology 228, 153-172.

732 Folk, R.L., 1974. The petrology of sedimentary rocks. Hemphill Publishing Co., Austin, Texas., $182 \mathrm{pp}$.

Goff, J A., Jordan, T.H., 1988. Stochastic Modeling of Seafloor Morphology: Inversion of Sea Beam data for second-order statistics. Journal of Geophysical Research 93, 13,589-13,608.

Goff, J.A., Jordan, T.H., 1989. Stochastic Modeling of Seafloor Morphology: resolution of topographic parameters by Sea Beam data. IEEE Journal of Ocean Engineering 14, 326-337.

Goff, J. A., Holliger, K., Levander, A.R., 1994. Modal fields: A new method for characterization of random velocity heterogeneity. Geophysical Research Letters 21, 493496.

Goff, J.A., Olson, H.C., Duncan, C.S., 2000 Correlation of sidescan backscatter intensity with grain-size distribution of shelf sediments, New Jersey margin. Geo-Marine Letters 20, 43-49.

Goff, J.A., Kraft, B.J., Mayer, L.A., Schock, S.G., Sommerfield, C.K., Olson, H.C., Gulick, S.P.S., Nordfjord, S., 2004. Seabed characterization on the New Jersey middle and outer shelf: Correlability and spatial variability of seafloor sediment properties. Marine Geology 209, 147-172.

Goff, J.A., Mayer, L.A., Traykovski, P., Buyenevich, I., Wilkins, R., Raymond, R., Glang, G., Evans, R.L., Olson, H., Jenkins, C., 2005. Detailed investigation of sorted bedforms, or “rippled scour depressions,” within the Martha’s Vineyard Coastal Observatory, Massachusetts. Continental Shelf Research 25, 461-484. 
751 Goff, J.A., Jenkins, C., Calder, B., 2006. Maximum likelihood resampling of noisy, spatially correlated data. Geochemistry, Geophysics and Geosystems 7, doi:10.1029/2006GC001297.

753

Grune, D., Jacobs, C.J.H., 1990. Parsing Techniques - A Practical Guide. Ellis Horwood, Chichester, England, 320pp.

Hamilton, E.L., Bachman, R.T., 1982. Sound velocity and related properties in marine sediments. Journal of the Acoustical Society of America 72, 1891-1904.

Harris, C.K., Butman, B., Traykovski, P., 2003. Winter-time circulation and sediment transport in the Hudson Shelf Valley. Continental Shelf Research 23, 801-820.

Inman, D.L., 1952. Measures for describing the size distribution of sediments. Journal of Sedimentary Petrology 22, 125-145.

Jackson, D.R., Winebrenner, D.P., Ishimaru, A., 1986. Application of the composite roughness model to high frequency bottom scattering. Journal of the Acoustical Society of America 79, $1410-1422$.

Jakobsson, M., B. Calder, Mayer, L., 2002. On the effects of random errors in gridded bathymetric compilations. Journal of Geophysical Research 107, doi:10.1029/2001JB000616.

Jenkins, C.J. 1997. Building offshore soils databases. Sea Technology 38, 25-28.

Jenkins, C.J. 2002. Automated digital mapping of sediment colour descriptions. Geo-Marine Letters 22, 181-187.

Jenkins, C.J., Goff, J.A., submitted. Competent interpolation for seabed substrates, with uncertainty calculations. Continental Shelf Research. 
772 Jones, M.B., Schildhauer, M.P., Reichman, O.J., Bowers, S. 2006. The New Bioinformatics:

773 Integrating Ecological Data from the Gene to the Biosphere. Annual Review of Ecology,

$774 \quad$ Evolution, and Systematics 7, 519-544.

775 Kerr, J.T., Southwood, T.R.E., Cihlar, J., 2001. Remotely sensed habitat diversity predicts

776 butterfly species richness and community similarity in Canada. Proceedings of the National

$777 \quad$ Academy of Sciences 98, 11,365-11,370

778 Lapinski, A-L.S., Chapman, D.M.F., 2005. The effects of ignored seabed variability in 
Poppe, L.J., Eliason, A.H., Fredericks, J.J., Rendigs, R.R., Blackwood D., Polloni, C.F., 2001. USGS East-coast sediment analysis: Procedures, database and georeferenced displays, U.S. Geological Survey Open File Report 00-358. On line at "http://pubs.usgs.gov/of/2000/of00358/text/contents.htm.”

Poppe, L.J., Paskevich, V.F., Williams, S.J., Hastings, M.E., Kelly, J.T., Belknap, D.F., Ward, L.G., FitzGerald, D.M., Larsen, P.F., 2003. Surficial sediment data from the Gulf of Maine, Georges Bank and vicinity: a GIS compilation. U.S. Geological Survey Open-file Report 03001, CD-ROM. Online at "http://pubs.usgs.gov/of/2003/of03-001/”.

Poppe, L.J., Williams, S.J., Paskevich, V.F., Eds., 2005. USGS East-coast sediment analysis: procedures, database, and GIS data. U.S. Geological Survey Open-File Report 2005-1001, DVD-ROM. Online at: “http://woodshole.er.usgs.gov/openfile/of2005-1001/”.

Pratson, L.F., Edwards, M. H., 1996. Introduction to advances in seafloor mapping using sidescan sonar and multibeam bathymetry. Marine Geophysical Research 18, 601-605.

Reid, J.M., Reid, J.A., Jenkins, C.J., Hastings, M.E., Williams, S.J., Poppe, L.J, 2005. usSEABED: Atlantic coast offshore surficial sediment data release. U.S. Geological Survey Data Series 118, version 1.0. Online at http://pubs.usgs.gov/ds/2005/118/.

Reid, J.A., Reid, J.M., Jenkins, C.J., Zimmermann, M., Williams, S.J., Field, M.E., 2006. usSEABED: Pacific Coast (California, Oregon, Washington) Offshore Surficial-Sediment Data Release: U.S. Geological Survey Data Series 182, version 1.0. Available online at http://pubs.usgs.gov/ds/2006/182.

Reineck, H.E., Singh, I.B., 1980. Depositional Sedimentary Environments with References to Terrigenous Clastics: 2d ed. Springer-Verlag, New York, 549 pp. 
815 Schwab, W.C., Thieler, E.R., Allen, J.R., Foster, D.S., Swift, B.A., Denny, J.F., 2000. Influence

816 of inner-continental shelf geologic framework on the evolution and behavior of the barrier-

817 island system between Fire Island Inlet and Shinnecock Inlet, Long Island, New York.

$818 \quad$ Journal of Coastal Research 16, 2, 408-422.

819 Smith, K.R., McConnaughey, R.A. 1999. Surficial sediments of the eastern Bering Sea

820 continental shelf: EBSSED database documentation. U.S. Dep. Commer., NOAA Tech.

$821 \quad$ Memo. NMFS-AFSC-104, 41p.

822 Smith, W. H. F., Wessel, P., 1990. Gridding with continuous curvature splines in tension.

$823 \quad$ Geophysics 55, 293-305.

824 Stoll, R.D., 1977. Acoustic waves in ocean sediments. Geophysics 42, 715-725.

825 Vincent, C.E., Swift, D.J.P., Hillard, B., 1981. Sediment transport in the New York bight, North 826 American Atlantic shelf. Marine Geology 42, 369-398.

Wessel, P., W H.F. Smith, 1998. New, improved version of the Generic Mapping Tools released. EOS Transactions of AGU 79, 579.

Williams, S. J., Jenkins, C., Currence, J., Penland, S., Reid, J., Flocks, J., Kindinger, J., Poppe, L., Kulp, M., Manheim, F., Hampton, M., Polloni, C., Rowland, J., 2003. New digital geological maps of U.S. continental margins: insights to sea floor sedimentary character, aggregate resources and processes. Proceedings of the International Conference on Coastal Sediments 2003, Corpus Christi, Texas, World Scientific Publishing Corporation and East Meets West Productions, Corpus Christi, Tex., 11 p., CD-ROM.

Williams, S.J., Arsenault, M.A., Poppe, L.J., Reid, J.A., Reid, J.M., Jenkins, C.J., 2006a. Surficial sediment character of the New York-New Jersey offshore continental shelf region; a 
837 GIS compilation: U.S. Geological Survey Open-File Report 2006-1046. Online at $838 \quad$ http://pubs.usgs.gov/of/2006/1046.

839 Williams, S.J., Reid, J.A., Arsenault, M.A., Jenkins, C., 2006b. Characterization of sedimentary 840 deposits using usSEABED for large-scale mapping, modeling and research of U.S.

841 continental margins. Eos Transactions of AGU 87, Fall Meeting Supplement, Abstract

$842 \quad$ H33B-1505.

843 Zadeh, L.A., 1965. Fuzzy Sets. Information and Control 8, 338-353. 


\section{$844 \quad$ Figure Captions}

845 Figure 1. Location map of current (2007) usSEABED data coverage (250,000 records), color

846 coded by mean grain size (Williams, et al., 2006b).

847

Figure 2. Conformance test between various measures of grain size: median, mode, Inman

849 graphical mean, and moment mean. Moment mean grain size (1:1 line) is the accepted standard.

850 The others deviate to a degree which may be compensated for in the processing of the analytical

851 data. Based on 3813 samples from USGS laboratories (Reid, et al., 2005; Poppe et al., 2005).

852

Figure 3. Example calibration of parsed and extracted mean grain size using samples where both

854 are available. The statistics are based on 10,029 sediment samples in the usSEABED database.

Figure 4. Location of usSEABED records within the mid-Atlantic Bight, color coded by mean grain size, and overlain on bathymetric contours (meters). Sample areas defined for this region are indicated by green polygons with yellow boarders.

Figure 5. Sample areas defined over the entire usSEABED database, color coded by the average

861 of the parsed mean grain size measurements within the sample area. Numbered identifications

862 provide reference for Table 1 statistical parameters.

864 Figure 6. A binned semivariogram (solid) derived from parsed mean grain size measurements in 865 the 0-20 m depth range of the New York Bight (Figure 4). The best-fit von Kármán model with 
866 noise spike is overlain (dashed), with parameter values as indicated. The fractal dimension of 867 the model is 1.5 , which corresponds to an exponential curve.

868

Figure 7. Plot of mean grain size estimated via extracted versus parsed methods, where samples of each type are separated by less than $200 \mathrm{~m}$. Binned averages are also shown, both for 871 extracted and parsed bins.

872 873
Figure 8. Semivariograms derived from both extracted and parsed mean grain size measurements within three sample areas: (a) the New York Bight, 0-20 m; (b) the Gulf of the Farallons, CA 0-150 m; and (c) Gulf of Maine just north of Cape Ann, 50-100 m. Area numbers refer to identifications in Figure 5. Best fit von Kármán models are overlain in dashed lines, with parameters as indicated.

Figure 9. Plots of extracted versus parsed statistical parameters from sample areas with adequate coverage of both types of data records. Dashed line indicates 1:1 correspondence. Circled symbols in (b) and (c) are from Gulf of Maine sample regions, and are discussed in the text. Correlation coefficients $(\rho)$ are given for each plot, neglecting the outliers identified in (b) and (c).

Figure 10. Sample areas color coded by estimated field variance of mean grain size measurements. In regions where both extracted and parsed estimates are made, the maximum value is displayed. Numbered identifications provide reference for Table 1 statistical parameters. 
889 Figure 11. Sample areas color coded by estimated decorrelation distance of mean grain size 890 measurements. In regions where both extracted and parsed estimates are made, the average 891 value, weighted by the number of samples of each, is displayed. Numbered identifications 892 provide reference for Table 1 statistical parameters.

893

894 Figure 12. Interparameter plots of statistical parameters estimated from usSEABED mean grain 895 size measurements. Sample areas are coded by parsed (PRS) or extracted (EXT), and by shelf 896 region $(\mathrm{ATL}=$ Atlantic; $\mathrm{GMX}=$ Gulf of Mexico; PAC $=$ Pacific $)$. The data points in $(\mathrm{b})$ are 897 reproduced from those in (a), but without the values from the Gulf of Maine and the Florida 898 shelf. These samples typically display very high variances, probably in association with the 899 presence of gravel or shell patchiness. The remainder exhibit a clear trend, both for parsed and 900 extracted measurements, which are illustrated with the dashed lines. Trends are otherwise not 901 evident in the other interparameter plots displayed.

902

Figure 13. (a) Kriging interpolation of the usSEABED mean grain size data off the Long Island shelf to $50 \mathrm{~m}$ water depth. The statistical parameters noted on Figure 6 were utilized in the

905

906

907 908 909 910 911
Figure 14. Comparison of overlapping portions of USGS acoustic backscatter data (a; from Schwab et al., 2000) and the interpolated, resampled mean grain size off the western Long Island shelf (b; from Figure 13b). Lighter shades indicate in (a) higher backscatter and coarser 
912 sediment, darker shades indicate lower backscatter and finer sediments. Bathymetric contours on 913 both plots, from the NOAA (2007) coastal relief model, are in meters.

914

915 Figure 15. Comparison of coregistered values (black dots) for backscatter intensity (Figure 14a) 916 and interpolated mean grain size (Figure 14b). Backscatter values, originally gridded at $4 \mathrm{~m}$, are 917 averaged within 0.00167-degree cells (approximately $200 \mathrm{~m}$ ). Cyan diamonds indicate average 918 backscatter values within $0.25-\phi$ grain size bins. 


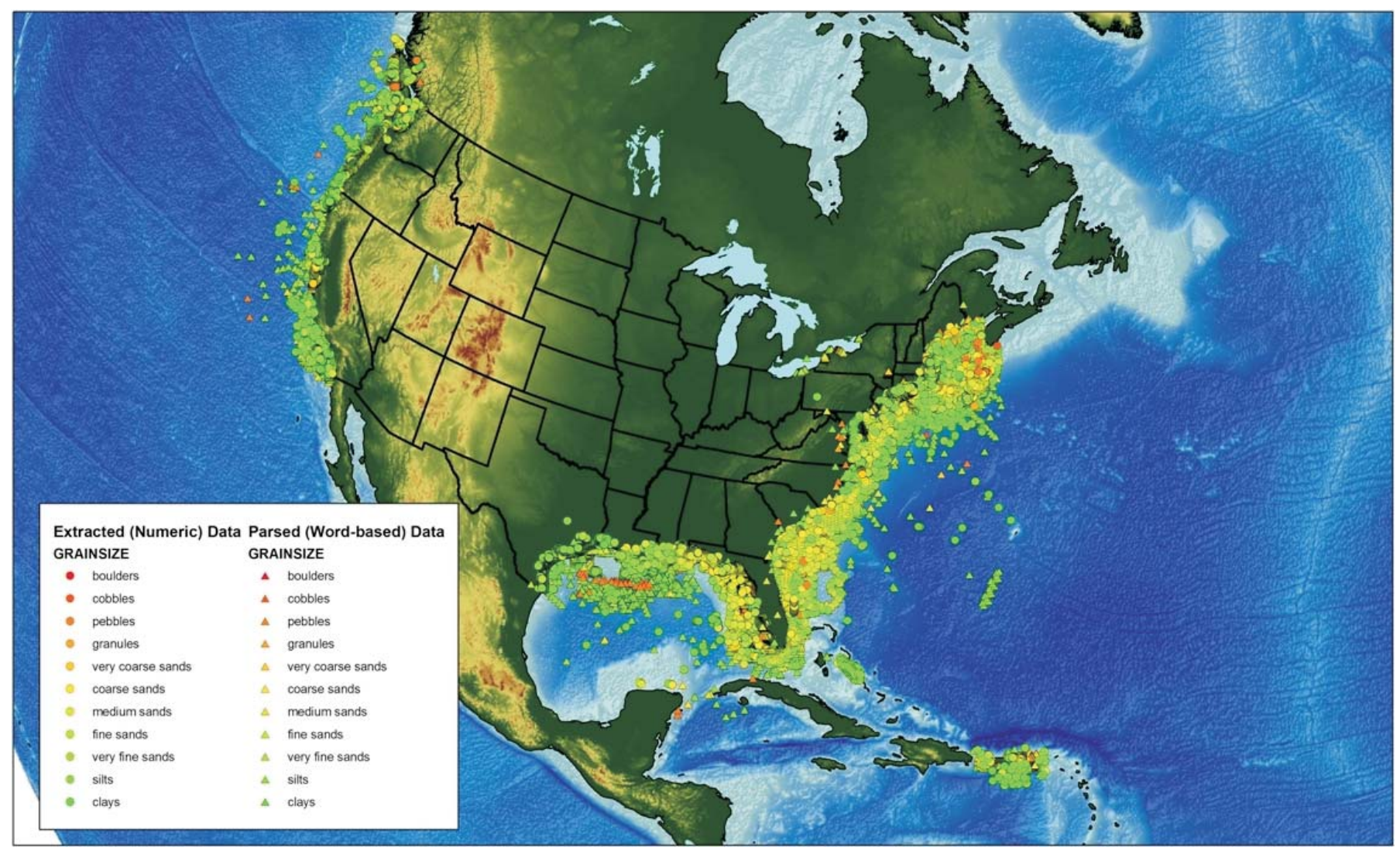

Figure 1 


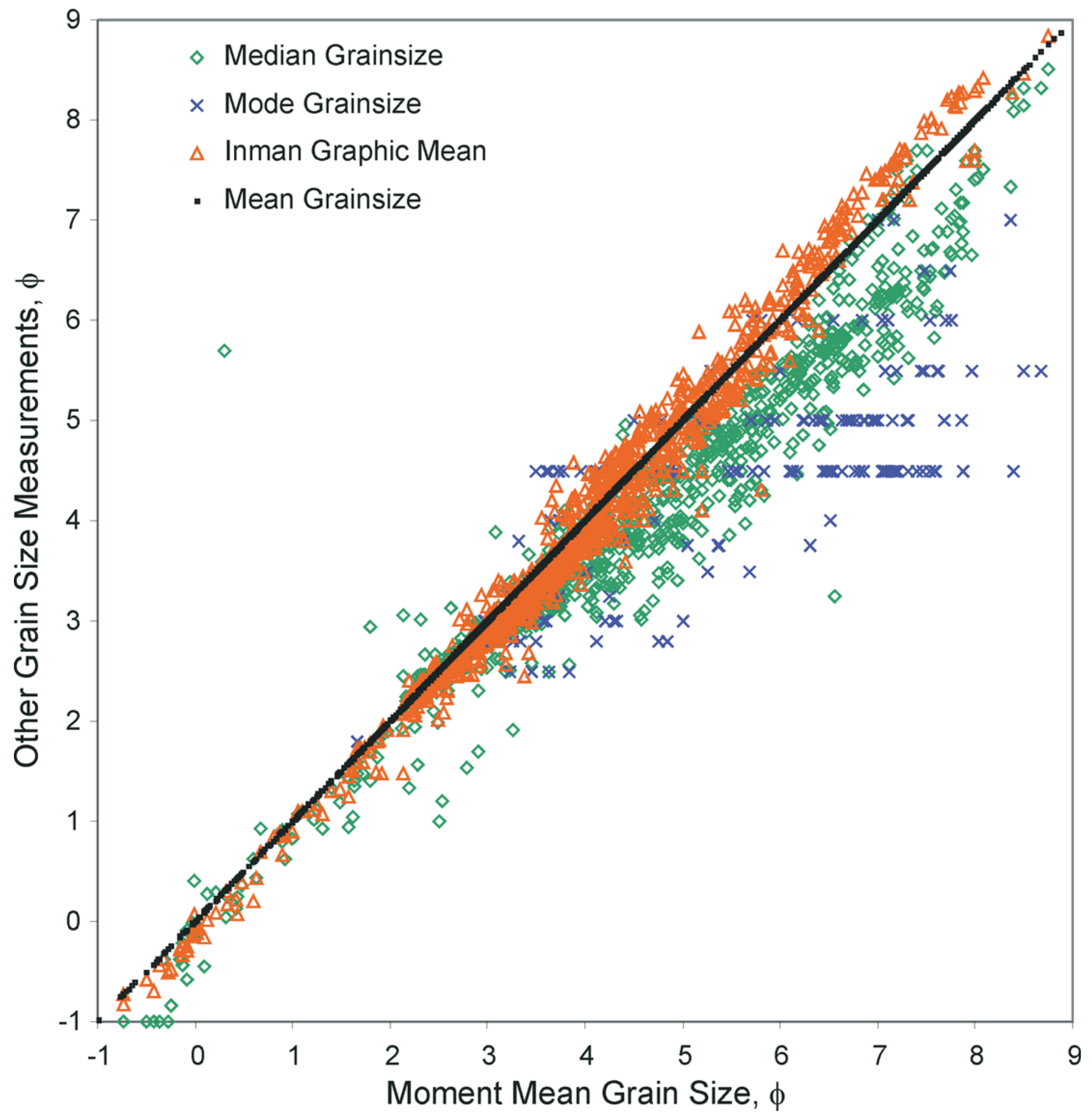

Figure 2 


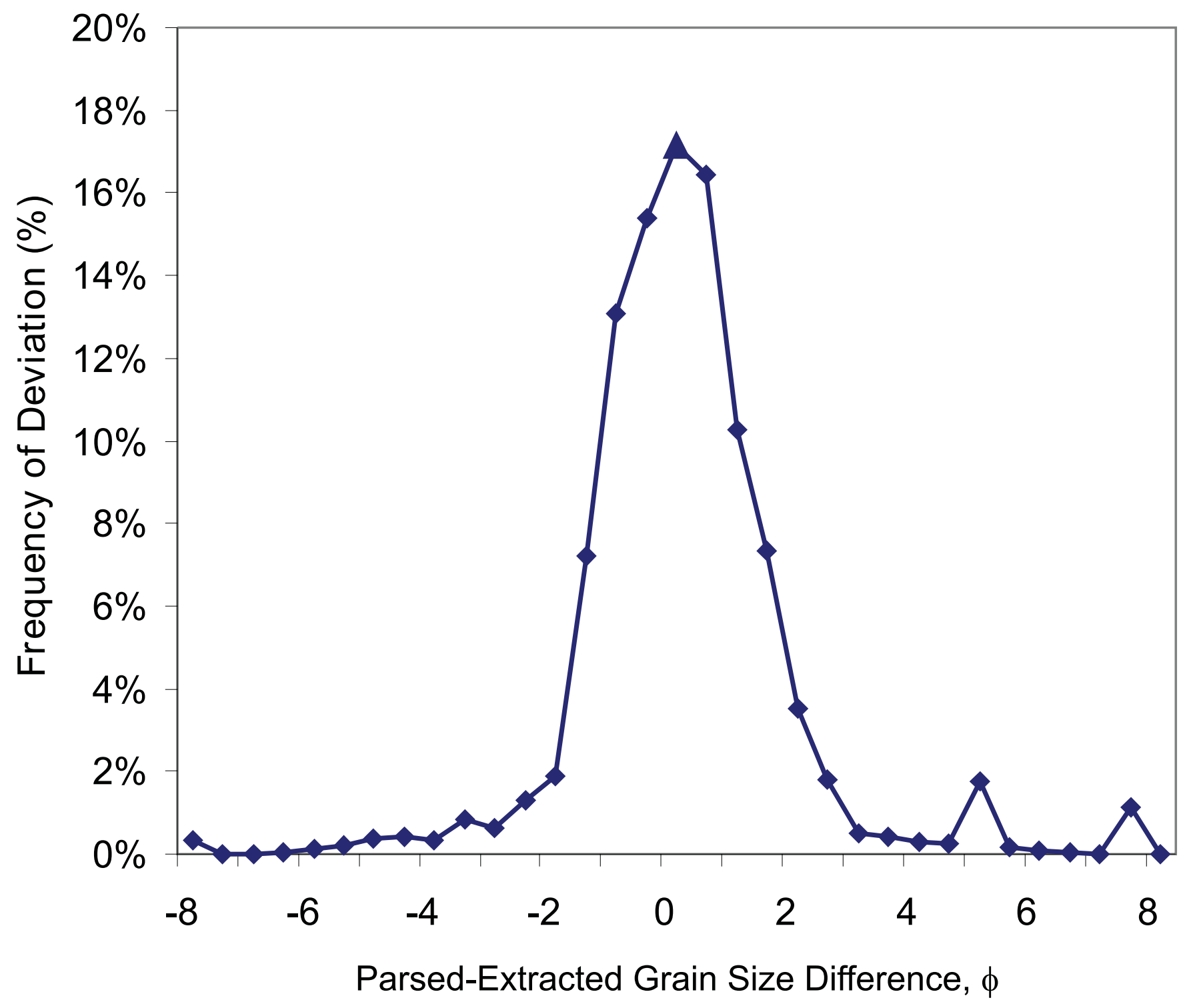

Figure 3 


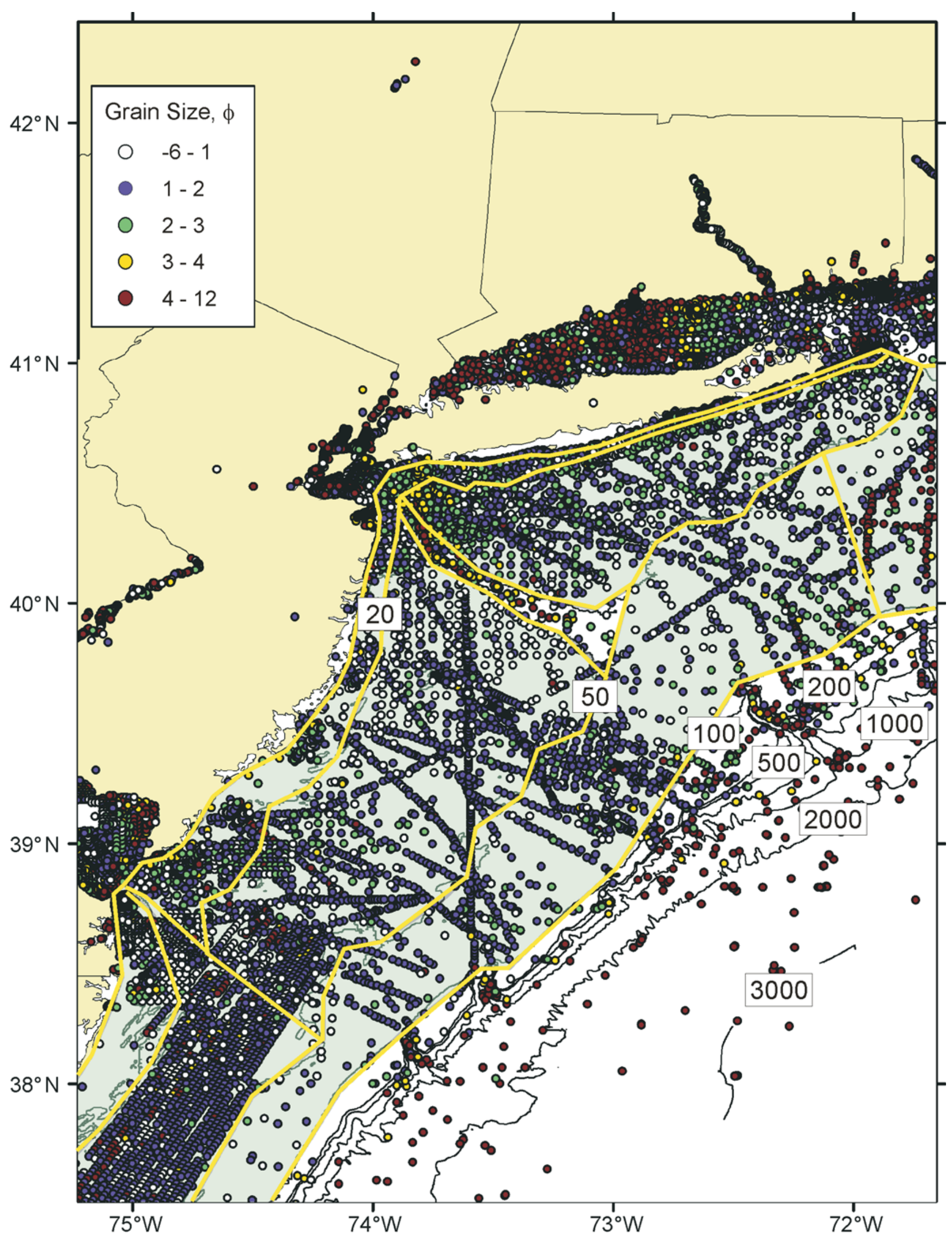

Figure 4 


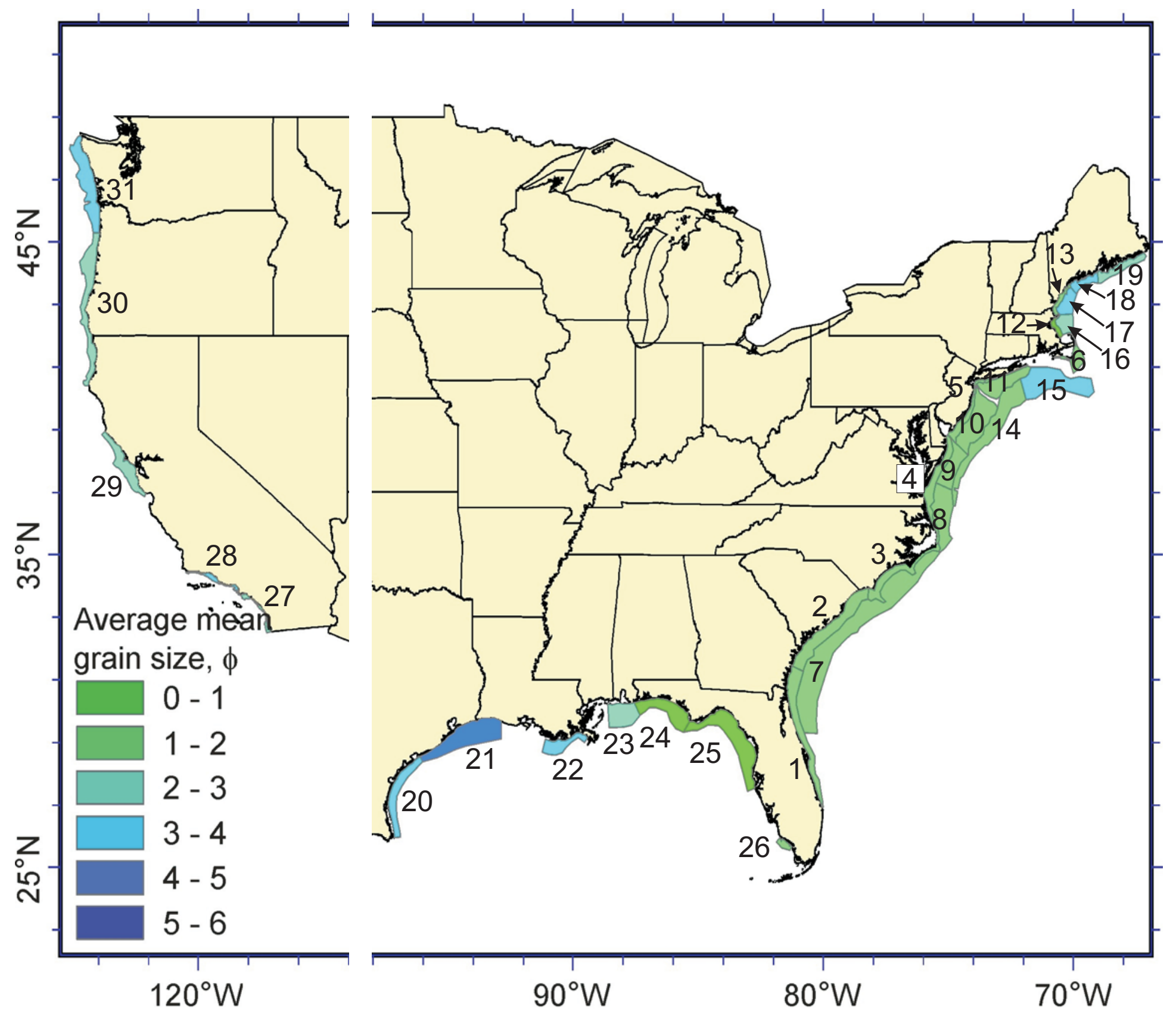

Figure 5 


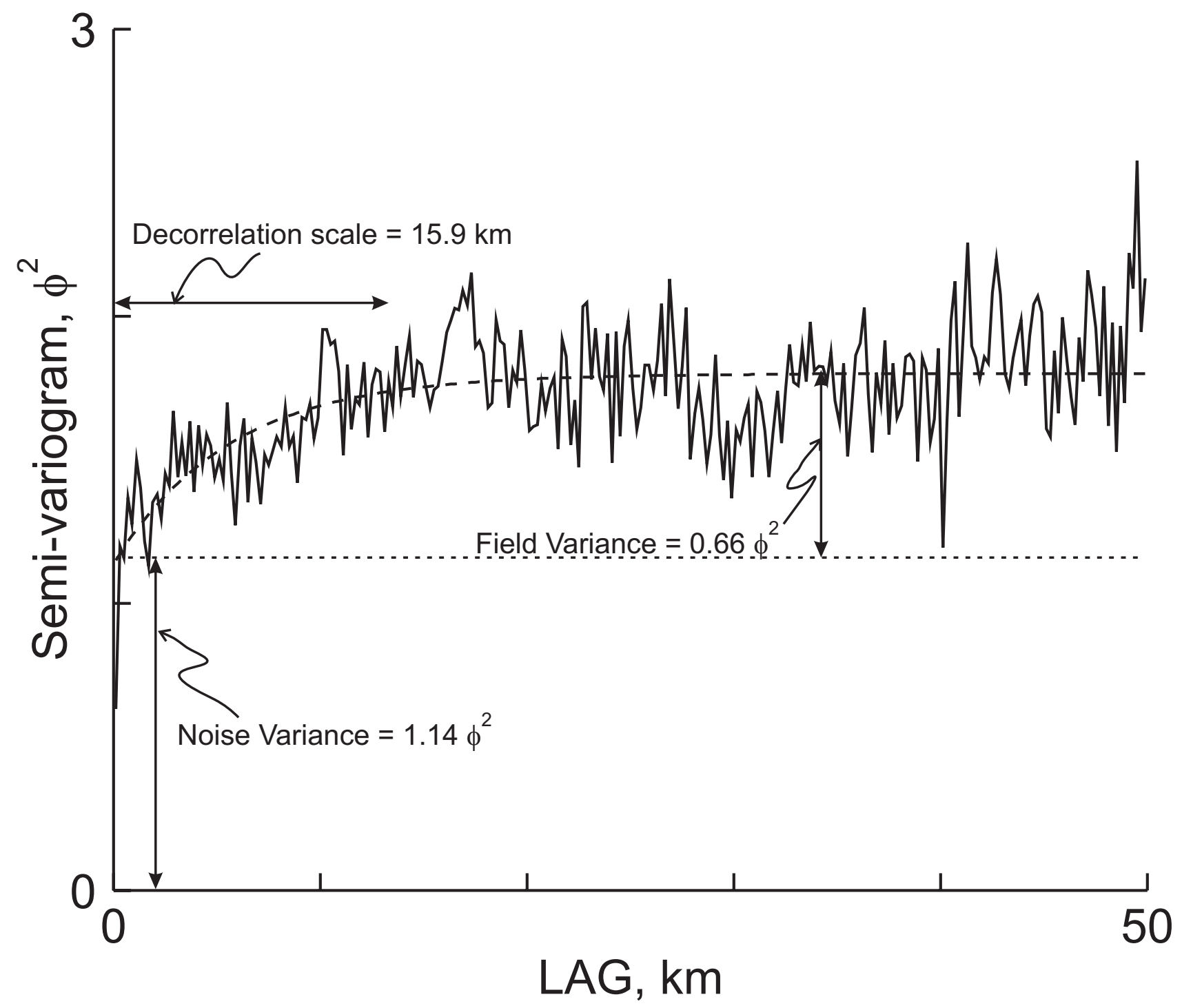

Figure 6 


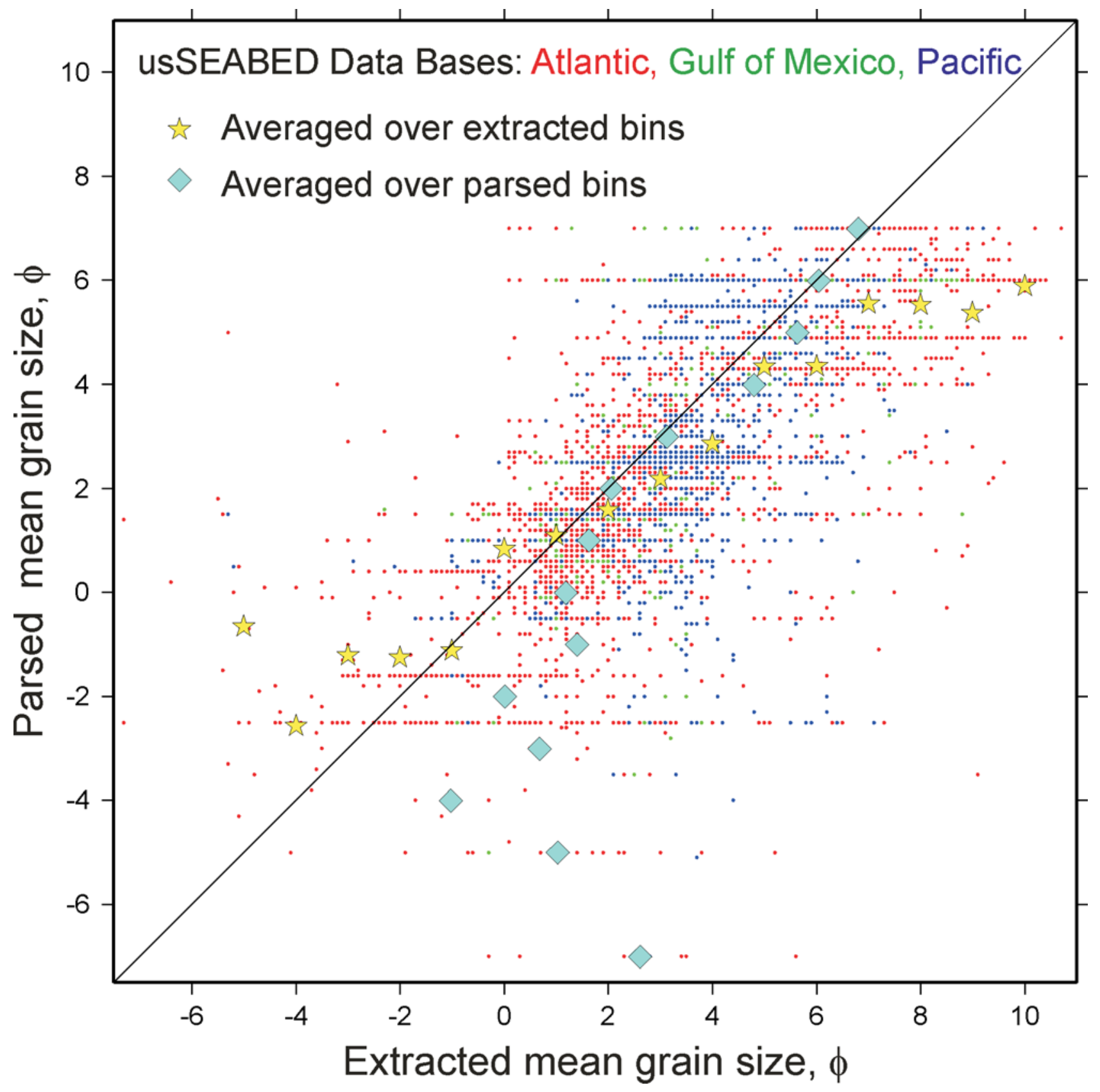

Figure 7 
a
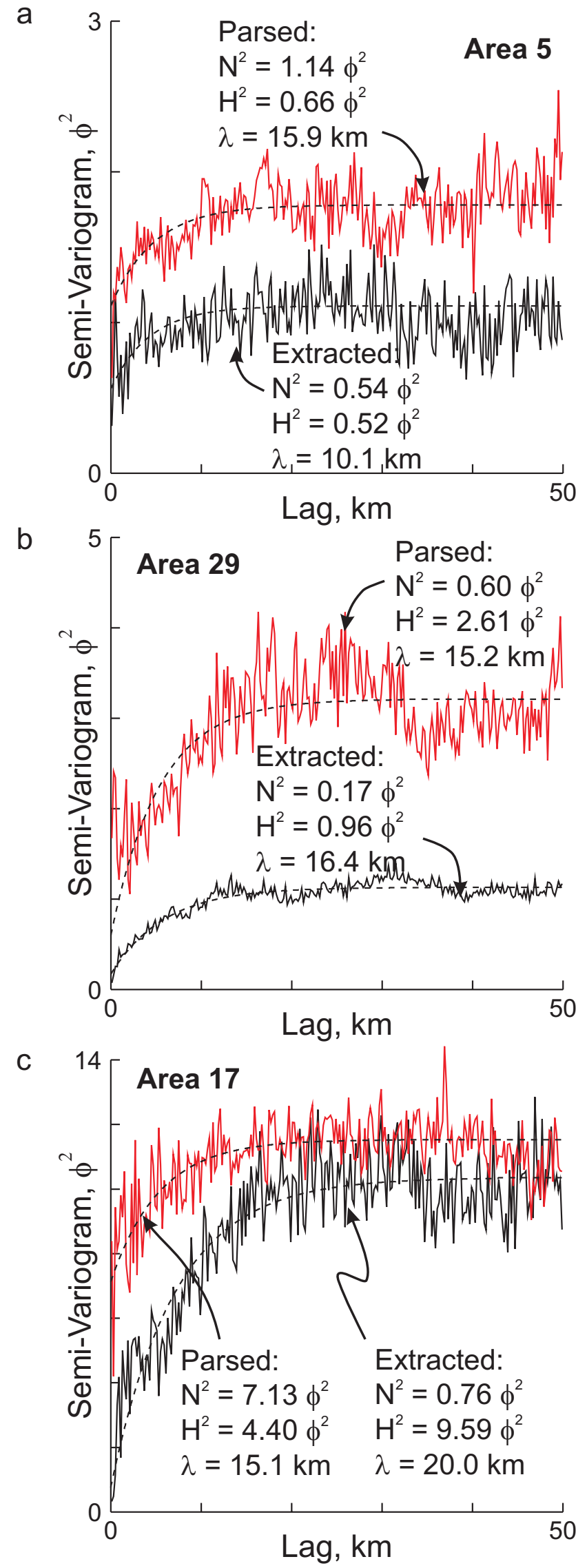

Figure 8 

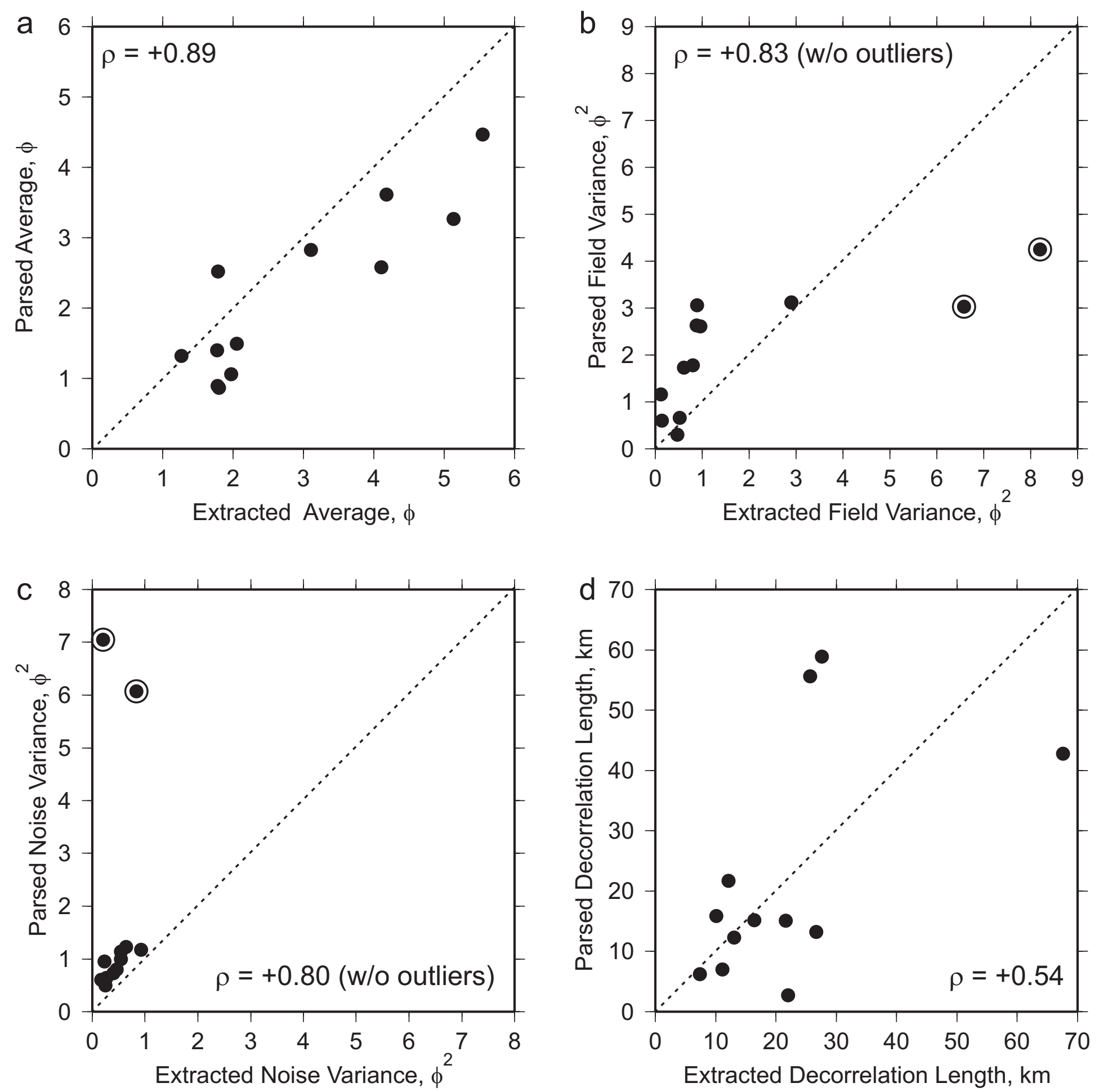

Figure 9 


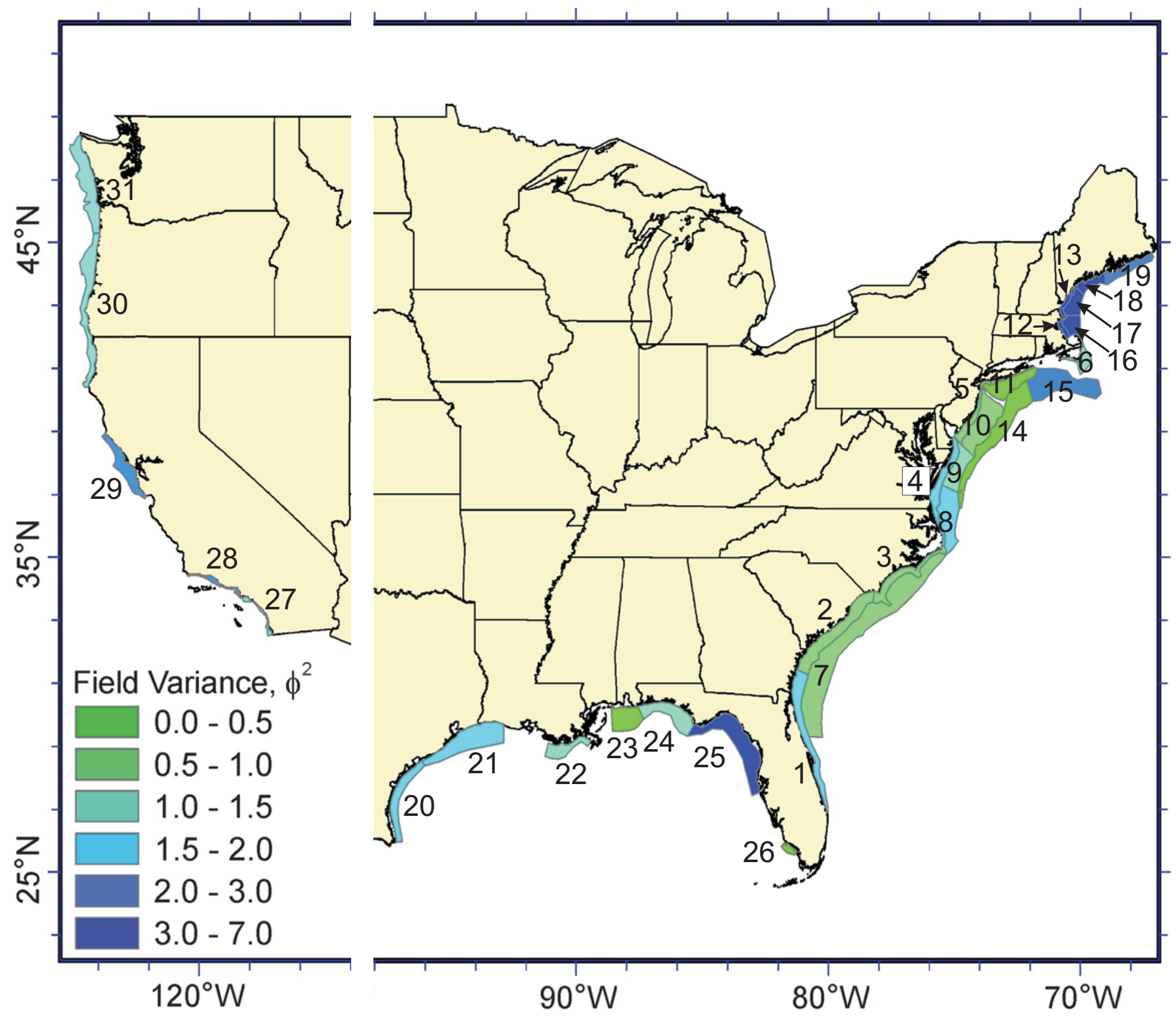

Figure 10 

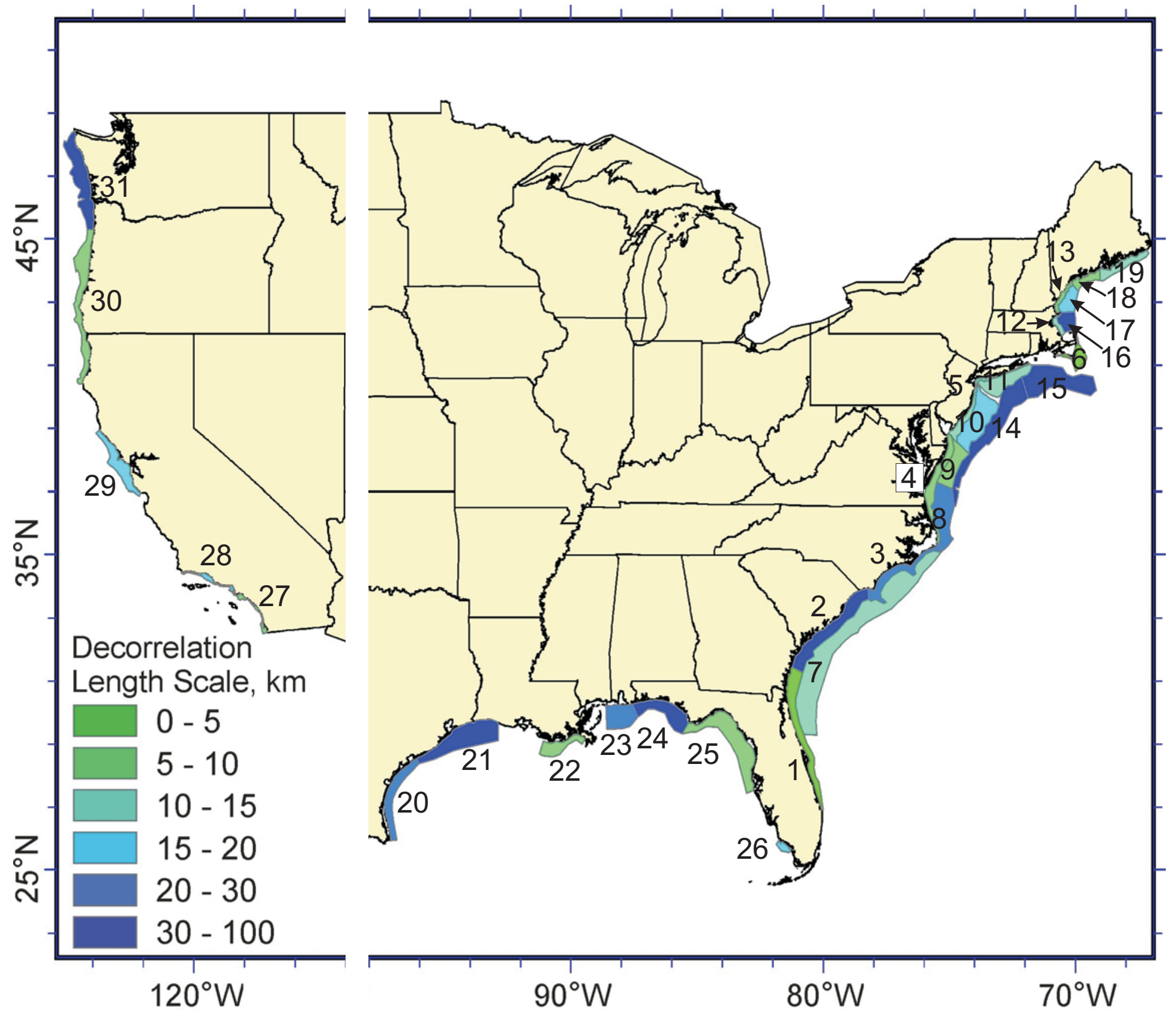

Figure 11 

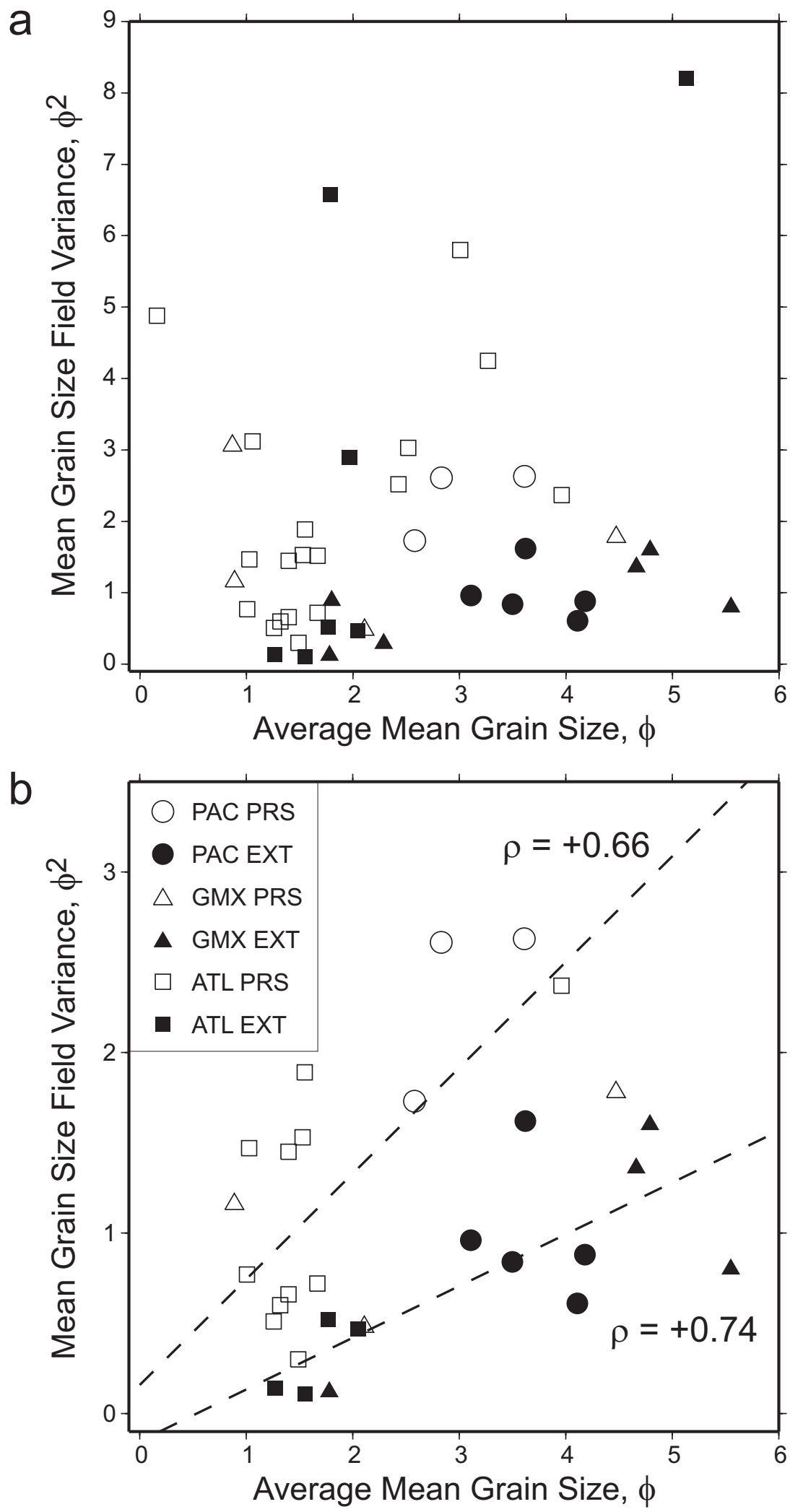

Figure 12 

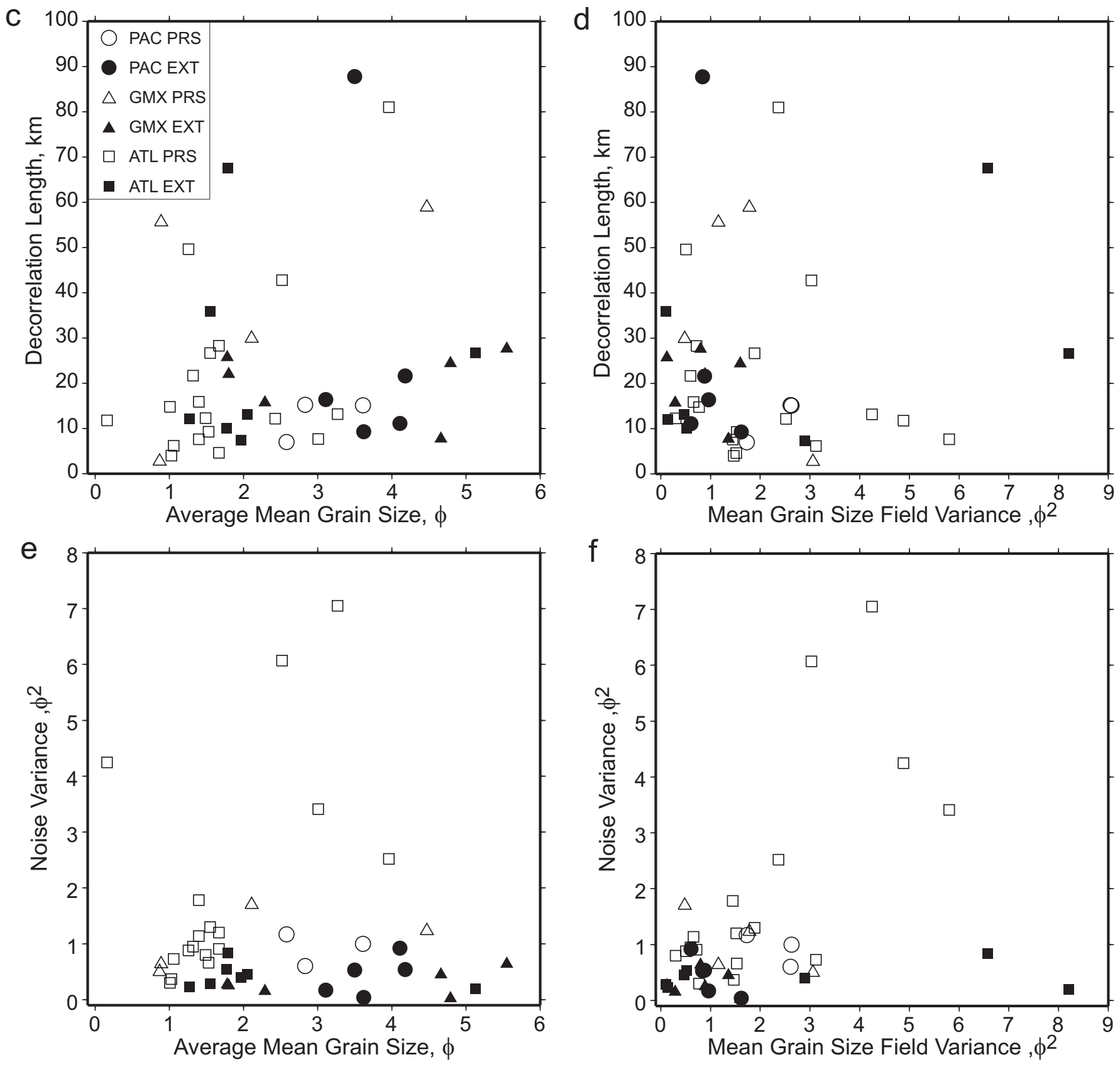

Figure 12 cont. 

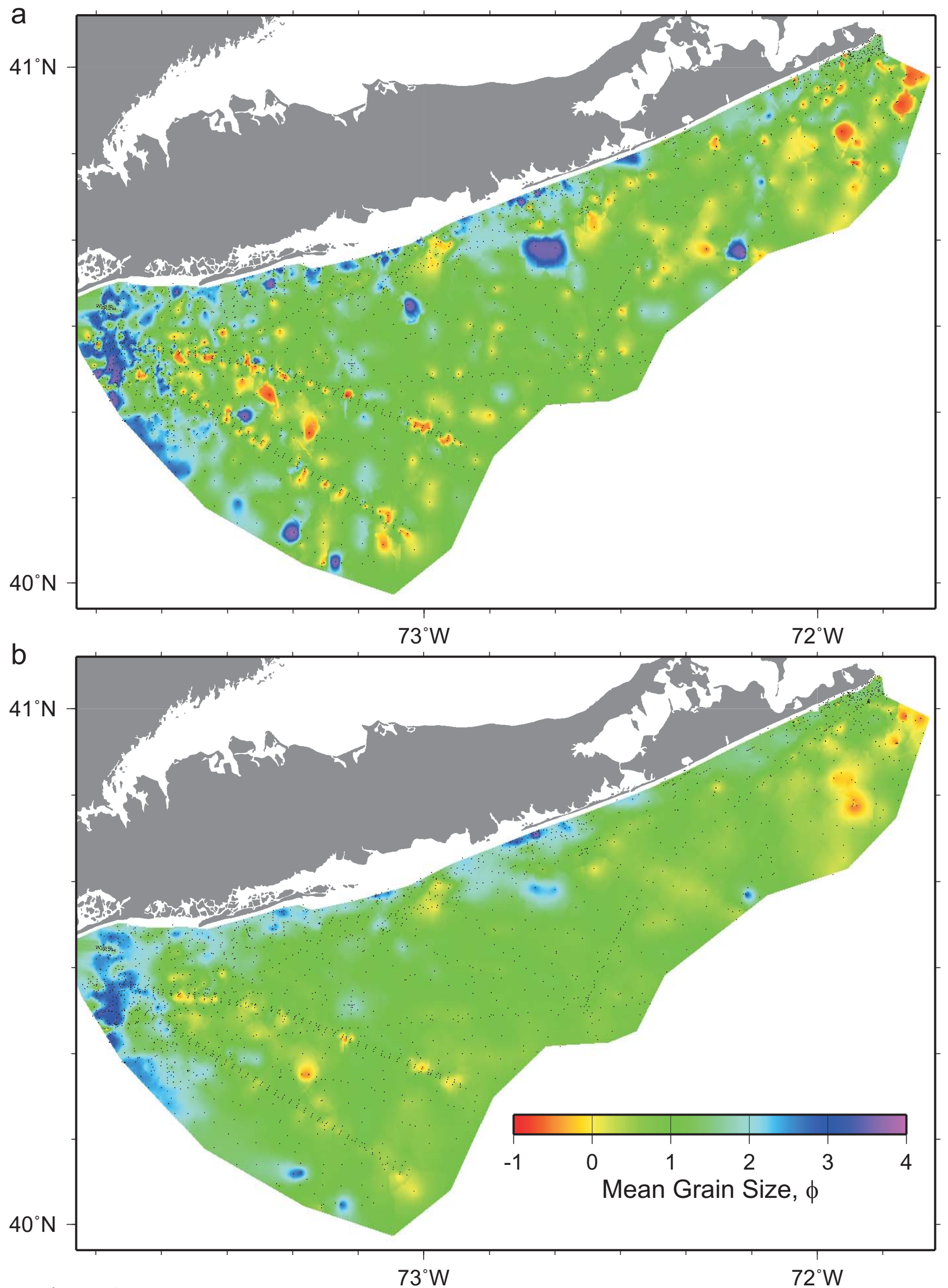

Figure 13 

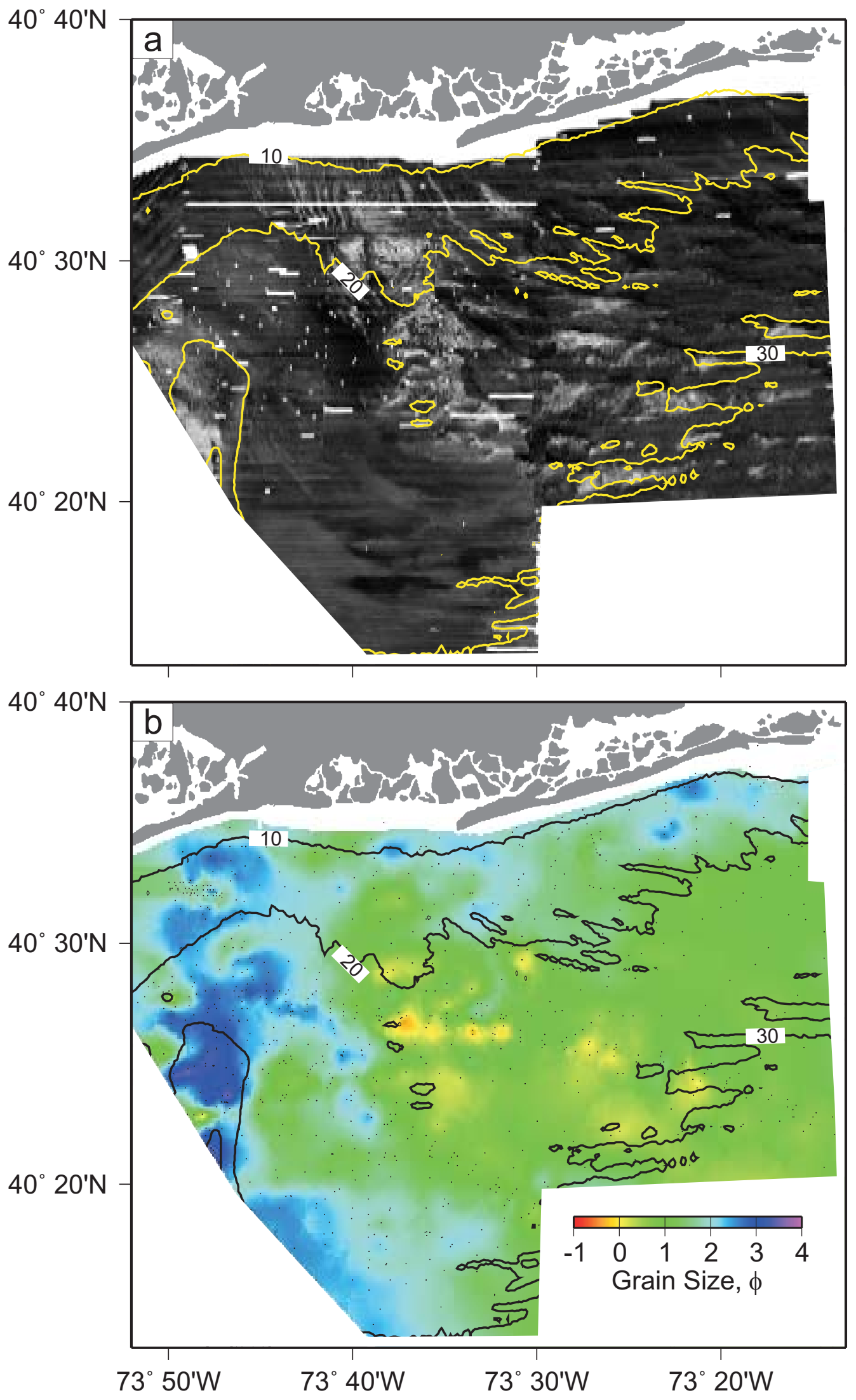

Figure 14 


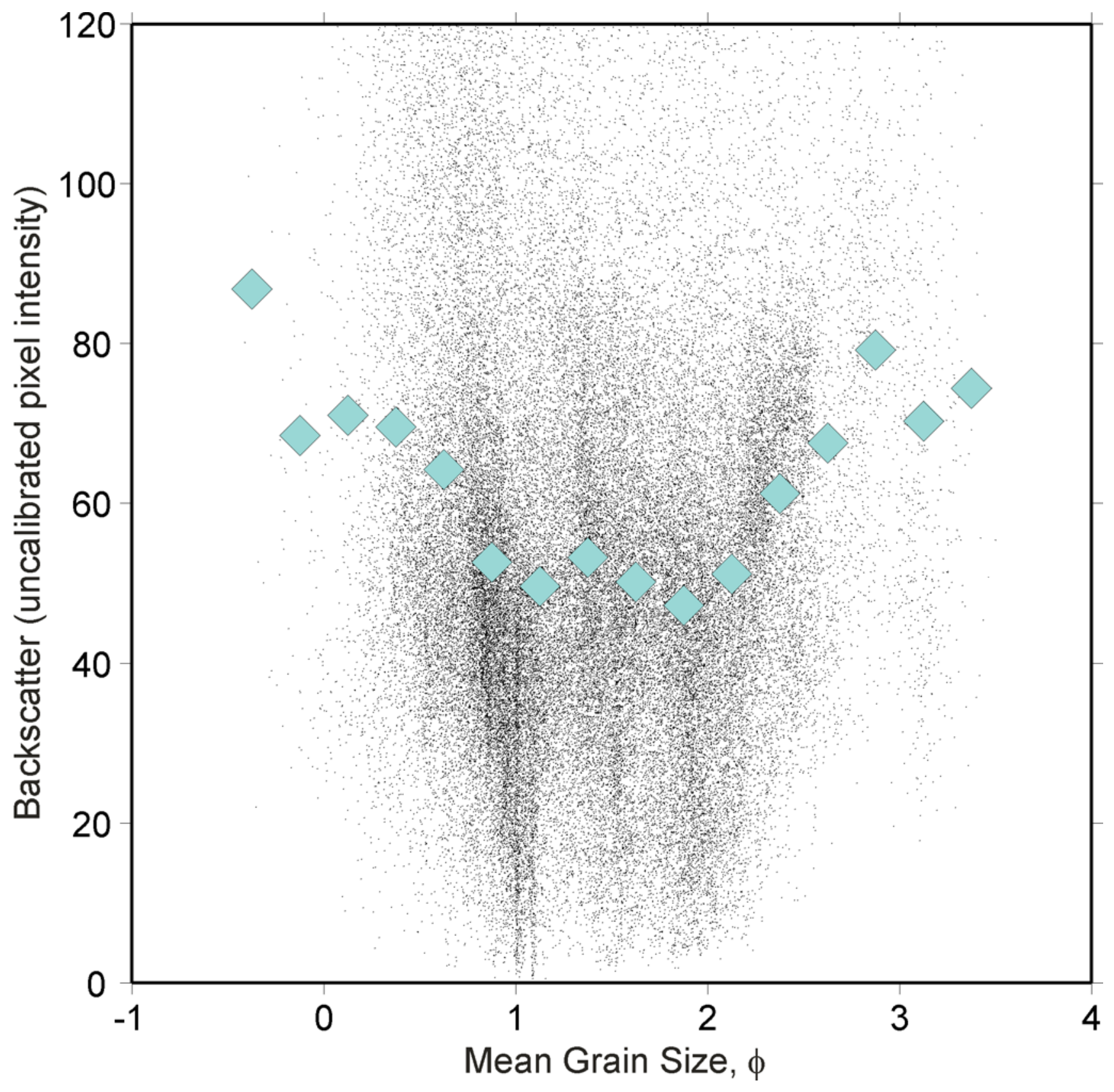

Figure 15 